\title{
Hybrid Wing Body Aircraft Acoustic Test Preparations and Facility Upgrades
}

\author{
Stephanie L. Heath ${ }^{\dagger}$, Thomas Brooks ${ }^{\ddagger}$, Florence Hutcheson ${ }^{\star}$, Michael J. Doty ${ }^{*}$, Henry H. Haskin ${ }^{\dagger}$, Taylor Spalt ${ }^{\S}$, \\ Christopher Bahr ${ }^{\dagger}$, Casey Burley ${ }^{\star}$, Scott Bartram ${ }^{\mathfrak{f}}$, William Humphreys ${ }^{\dagger}$, Charles B. Lunsford ${ }^{\circ}$, Thomas Popernack ${ }^{£}$ \\ and Scott Colbert ${ }^{£}$ \\ NASA Langley Research Center, Hampton, VA, 23681 \\ Danny Hoad ${ }^{\eta}$, Lawrence Becker ${ }^{\eta}$ and Daniel Stead ${ }^{\eta}$ \\ Northrop Grumman \\ Dennis Kuchta ${ }^{+}$and Les $\mathrm{Yeh}^{\S}$ \\ Jacobs Sverdrup ROME, NASA Langley Research Center, Hampton, VA, 23681
}

\begin{abstract}
A hybrid wing body transport aircraft model was tested in NASA Langley's 14 by 22Foot Subsonic Tunnel to evaluate proposed "low noise" technology. The experiment was set up to evaluate the community noise impact of the hybrid wing body design, as well as study the noise components of propulsion-airframe noise and shielding. A high fidelity 5.8-percent scale model, including landing gear, cruise and drooped wing leading edges, trailing edge elevons, vertical tail options, and engine noise simulators, was built to test both aerodynamic and acoustic configurations. The aerodynamic test data were used to establish appropriate flight conditions for the acoustic test.

To accomplish the acoustic portion of this test, two major upgrades were required of NASA Langley's 14 by 22 Foot Subsonic Tunnel; first, a fuel delivery system to provide realistic gas temperatures to the jet engine simulators; and second, a traversing microphone array and side towers to measure full spectral and directivity noise characteristics.

The results of this test provide benchmark hybrid wing body aircraft and noise shielding data to assist in achieving NASA's 2020 noise emission goals.
\end{abstract}

\section{Introduction}

To achieve the next generation of aircraft noise reductions, the aircraft noise research community must search beyond traditional airframe and engine noise sources. When the propulsion system and airframe are considered as a unit, additional acoustic sources can be created or significantly altered. A complete high fidelity wind-tunnel model of the HWB system was built to develop, test and understand new aircraft propulsion aeroacoustic (PAA) technologies such as flows through and around the engines and airframe, shielding effects, and diffraction around aircraft edges.

The Hybrid Wing Body (HWB) aircraft configuration with the installation of the engines on the upper surface of the airframe and highly integrated fuselage and wings should yield quieter aircraft characteristics. To obtain accurate acoustic data on this unconventional HWB aircraft, it was important to have wind tunnel test conditions as close to real flight conditions as possible to capture all propulsion aircraft acoustic influences. The current test involves not

\footnotetext{
${ }^{\dagger}$ Research Aerospace Engineer, Aeroacoustics Branch, MS 461, Member AIAA

${ }^{\ddagger}$ Senior Research Scientist, Aeroacoustics Branch, MS 461, Fellow AIAA

* Senior Research Aerospace Engineer, Aeroacoustics Branch, MS 461, Senior Member AIAA

${ }^{£}$ Facility Systems Engineer, Subsonic Transonic Testing Branch, MS 289, Member AIAA

${ }^{\S}$ Research Student Trainee, Aeroacoustics Branch, MS 461, Student Member AIAA

${ }^{\circ}$ Research Aerospace Engineer, Advanced Sensing and Optical Measurement Branch, MS 493, Member AIAA

${ }^{\mathrm{T}}$ Senior Scientist, Advanced Sensing and Optical Measurement Branch, MS 493, Member AIAA

${ }^{£}$ Engineering Technician, Advanced Sensing and Optical Measurement Branch, MS 493, Member AIAA

${ }^{+}$Engineering Technician, MS 461

$\S$ Test Engineer, MS 289

${ }^{\eta}$ Senior Engineer, MS 461
} 
just shielding of the engine noise but also understanding and rearranging the noise sources to take advantage of shielding. Two types of engine noise simulators were used to test the effectiveness of engine shielding benefits: a broadband noise simulator to represent turbomachinery noise and a compact hot jet engine simulator to represent the jet noise.

This test is uniquely designed to demonstrate the achievability of the Agency goals by answering the question, "How much noise reduction can be achieved with a HWB concept"? The HWB assessment, anticipated in September 2013, will evaluate the progress toward achieving NASA's noise emission goals of 42 Effective Perceived Noise Levels in decibels (EPNL dB) cumulative noise below the Federal Aviation Administration (FAA) Federal Aviation Regulations (FAR) 36 Stage 4 certification level ${ }^{1}$.

The planning of these tests began in 2008 under NASA's Environmentally Responsible Aviation (ERA) project and was first presented to the aeroacoustic community in $2011^{2}$. The HWB aircraft was designed as a cargo plane with a 6000 nautical mile mission and a maximum payload of 103,000 pounds ${ }^{3}$. It was based on a new integrated planform with conventional state of the art dual engines. The research efforts were broken into two stages: an aerodynamic wind tunnel test in July $2011^{4}$ and an aeroacoustic test from September 2012 through January 2013. Both tests were conducted in Langley Research Center's 14 by 22 Foot Subsonic Tunnel. The 14x22 Tunnel was advantageous for the HWB acoustic test because of its size: To obtain full scale high frequency acoustics of interest, the corresponding wind tunnel model wing span was almost thirteen (13) feet. In addition, with some modifications to the tunnel, it was possible to invert the HWB model and sweep an acoustic array over a large range of directivity angles.

The Hybrid Wing Body (HWB) aircraft concept for this study was developed under a NASA Research Announcement (NRA) with Boeing. The Boeing team included the Massachusetts Institute of Technology (MIT), the University of California at Irvine (UCI), and the United Technologies Research Center to provide noise prediction assessments and test design support for the development of the HWB vehicle. As part of the noise assessment effort new noise shielding methods for installed turbomachinery and jet noise were developed with the intent of eventual integration into the Aircraft Noise Prediction Program (ANOPP ${ }^{5}$ ). ANOPP $2^{6}$ is being expanded to incorporate prediction capabilities for advanced unconventional vehicle designs such as the HWB.

The shielding results of the HWB test will be used to 1) determine the spectral levels and noise directivity of the HWB airframe and engine simulator components, 2) characterize noise shielding benefits of the HWB fuselage, and 3) provide a benchmark acoustic database of isolated and shielded components for development/validation of noise prediction capabilities including those of ANOPP and ANOPP2.

The purpose of this paper is two-fold. First, to document the Hybrid Wing Body (HWB) activities required in the investigation; and second, to inform the acoustic community of the new acoustic testing capabilities in NASA Langley Research Center's 14 by 22 Foot Subsonic Tunnel.

\section{Background and History}

The aircraft noise research community has significantly reduced aircraft noise over the past five decades through the development of advanced bypass ratio fans, advanced jet nozzles, and airframe noise reduction technologies. Figure 1 maps the historical reduction in commercial aircraft noise up to the present. Large jumps in noise reduction have been attributed to advancing engine technologies. As advances in engine noise technology with acceptable performance become more challenging, noise reduction becomes increasingly more difficult and it becomes necessary to look at other technologies to achieve further noise reduction.

The National Aeronautics Research and Development Plan ${ }^{7}$ designates "N+1", "N+2" and "N+3" successive notional aircraft generations to anchor the environmental goals. A HWB design with engines mounted on the upper surface for shielding benefits has been proposed as a means of meeting the $\mathrm{N}+2$ noise goals. It is anticipated that only half of the noise reduction assessed against the $\mathrm{N}+2$ goals will be attributable to engine technologies; thus to achieve further noise reduction, the community must investigate new aircraft configurations including shielding. In order to correlate NASA's cumulative noise reduction goals to an average noise reduction, as seen in Figure 1, the Environmentally Responsible Aviation (ERA) N+2 project goal of 42 EPNL dB cumulative reduction at the FAA's three certification points with an average reduction of 14 EPNL dB relative to stage 4. 


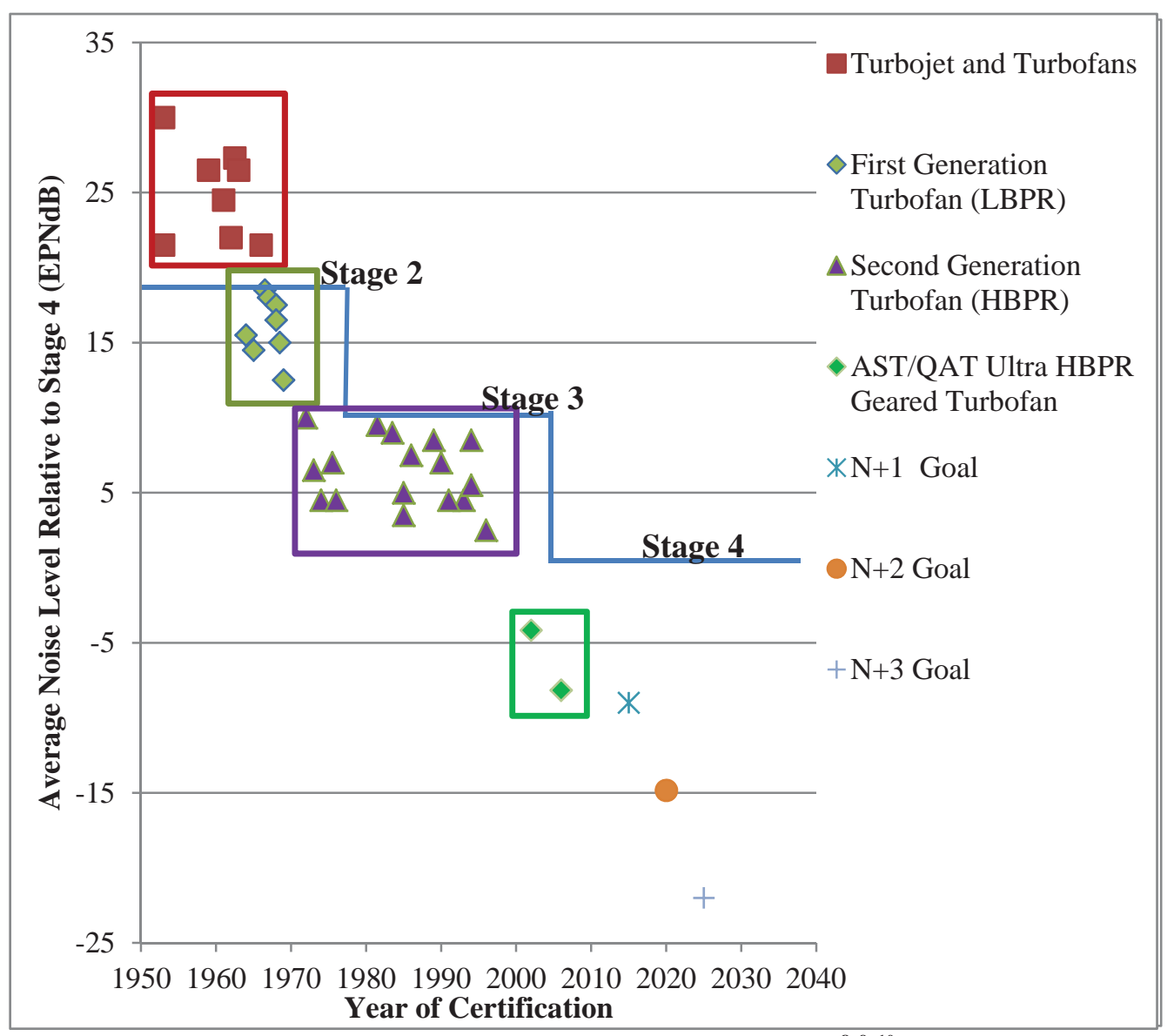

Figure 1. Normalized Average Historical Progress in Aircraft Noise Reduction ${ }^{8,9,10}$. The noise values are normalized to $100,000 \mathrm{lb}$ thrust. Significant noise reduction has been accompanied by engine technologies in the past. Note: Average EPLN values reflect 1/3 of the cumulative noise levels which include take-off, sideline/cutback and approach certification values.

Prior to undertaking this test, a pretest system noise assessment ${ }^{11}$ of the hybrid wing body with state-of-the-art engines was performed using NASA's best available aircraft models, engine models, and systems level code (ANOPP) to determine the probability of success in achieving NASA's N+2 acoustic goal. Where ANOPP prediction codes were inadequate, an experimental database containing suppression factors for key noise sources and interaction effects was directly input into the ANOPP noise assessment. In addition to the shielding database two codes, the Fast Scattering Code ${ }^{12}$ (FSC) and the Diffraction Integral Method Code ${ }^{13}$ (DIM), were used to predict noise scattering effects for the broadband fan noise, tonal fan noise and jet noise. Since the completion of the assessment, the diffraction code has been enhanced to account for more general reflections and edge effects, which for the HWB range from the sharp trailing edge to a more rounded blunt leading edge.

A post-test HWB assessment will demonstrate the viability of the HWB aircraft to achieve NASA's goals. But just as importantly, the results of this test will be used to update the shielding databases compiled over the last decade from the works of Clark and Gerhold ${ }^{14}$, Hill ${ }^{15,16}$, Reimann and Tinetti ${ }^{17}$, and most recently by Czech, Thomas, and Elkoby ${ }^{18}$, and to validate the scattering and diffraction codes.

\section{HWB Model}

The HWB model is $5.8 \%$ of full scale which easily allows acoustic measurements over the full scale equivalent range of about $230 \mathrm{~Hz}$ to $4.1 \mathrm{kHz}$ (4 to $70 \mathrm{kHz}$ model scale). The HWB low-speed wind tunnel model represents Boeing's Quiet R1 configuration aircraft, and is designated as N2A-EXTE. The HWB aircraft consists of wings which are highly integrated with the central fuselage and of accurately scaled details for airframe noise studies. The model was built by MicroCraft, Inc. under contract to Boeing and is illustrated in the expanded view presented in Figure 2. It measures 8.58 feet long with a span of 12.35 feet. 
The model is modular with components and control surfaces that may be deflected to match specific flight conditions. The components include drooped and cruise leading edges, trailing edge elevons, vertical tails, landing gear, and flow through nacelles (which are replaced during the acoustic testing with turbomachinery and jet noise simulators).

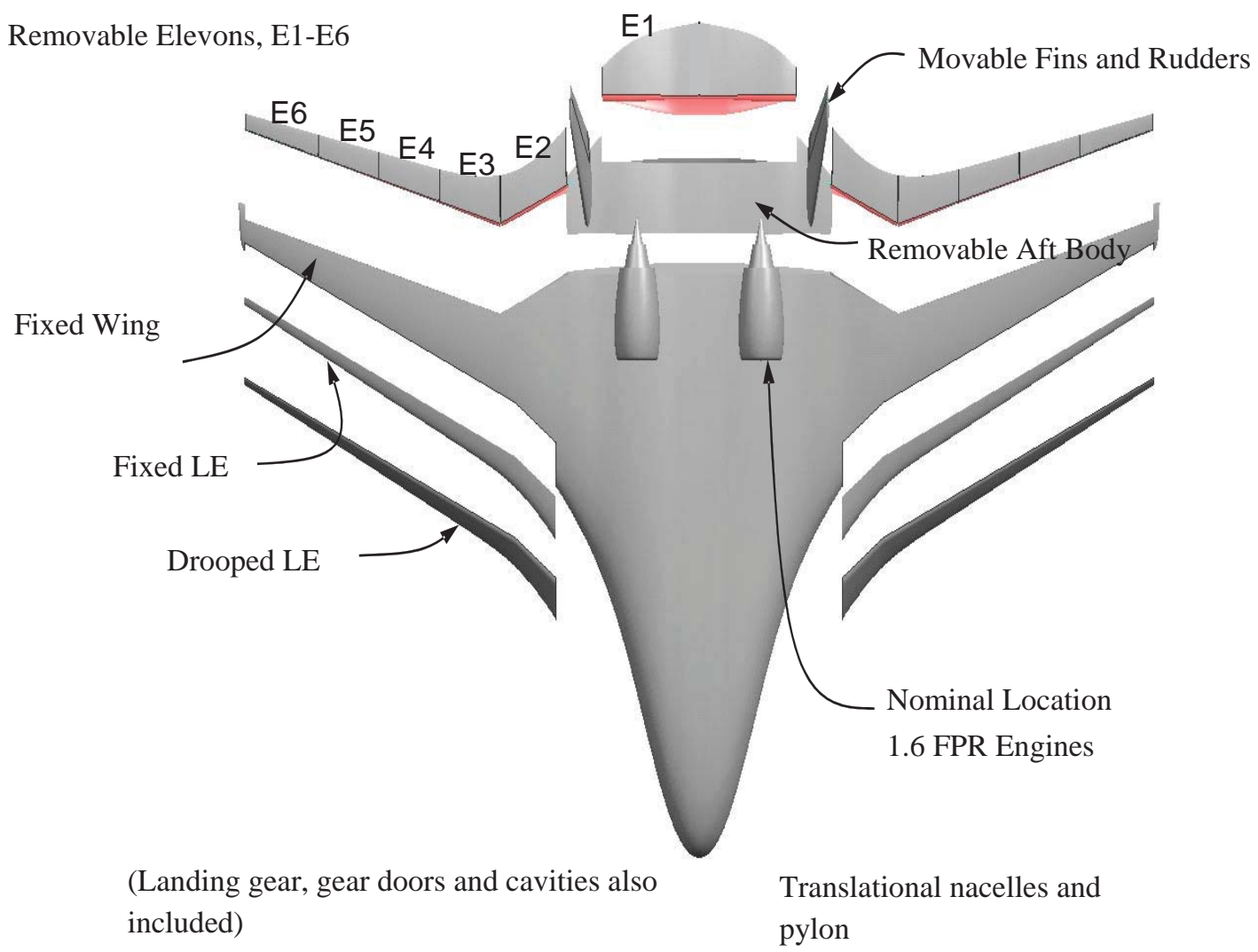

Figure 2. General HWB Model Arrangement.

The HWB wing is swept and has twist at the wingtip. The model reference area is $33.50 \mathrm{ft}^{2}$, with a reference chord of 60.55 inches and a model moment reference center at 54 percent of the fuselage length aft of the model nose. The model has removable, hinged leading edge shapes, one for cruise and one for the low-speed "drooped" leading edge. The drooped leading edge is deflected $20^{\circ}$ down at approximately $30 \%$ span and transitions to a deflection of $30^{\circ}$ between 40 and $45 \%$ span and then remains at $30^{\circ}$ deflection for the remainder of the outboard portion of the span.

The HWB model also supports various vertical tail configurations. These configurations include two vertical tail geometries (long span/short chords and short span/long chords) and two cant angles $\left(10^{\circ}\right.$ and $30^{\circ}$ ) for each tail geometry. The vertical tails can be located at either a forward or rear longitudinal position, and also support three rudder deflection angles. Referring to Figure 2, there are eleven independently deflectable elevons along the trailing edge of the vehicle. A center elevon (E1) positioned between the two vertical tails, and 5 elevons extending across the trailing edge of each wing. Each elevon can be set at $-40^{\circ},-10^{\circ}, 0^{\circ},+10^{\circ}$, or $+40^{\circ}$ deflection angles. The thickness of the model trailing edges is approximately 0.009 " which accurately represents a $5.8 \%$ scaling of the full size geometry.

Removable high-fidelity landing gears include left and right main gears and a nose gear. All gear components, hydraulic lines, actuators, side braces, brake system and tire treads are scaled. Gear wells and partially covered wheel wells and gear doors are also scaled. In addition to the landing gears, flow-through nacelles with pylons can be mounted on the fuselage upper surface at three different longitudinal stations.

The baseline model configuration for the HWB test consisted of the drooped leading edge, the nacelles (engine noise simulators) in the mid location, the longer span vertical tails mounted with a $10^{\circ}$ cant angle in the aft location, all elevons and rudders undeflected, the landing gear off, and the landing gear wells closed. 
The HWB model was instrumented with pressure taps, temperature sensors, and typical AOA (angle of attack) sensing devices. Two hundred and forty eight (248) surface static pressures were connected to the onboard electronically scanned pressure modules: 3 rows of 45 pressure taps located on the left hand wing of the model, 1 row of 45 pressure taps on the body, 64 pressure taps on the right hand wing and 4 internal static pressure orifices inside the starboard flow through nacelle, and two located in the balance cavity. There were four temperature sensors on the fuselage upper surface, just aft of the nacelles to monitor the fuselage temperature when the NASA Compact Jet Engine Noise Simulators were in use. In addition to pressure and temperature instrumentation, the model was equipped with 6 small compression speaker drivers. The drivers were embedded into the model and were used for tuning of microphone array processing. Four drivers were positioned in the center portion of the model and two were mounted in the wings.

\section{Engine Simulators}

Engine noise simulators were designed and developed to realistically model the engine noise sources. A Compact Jet Engine Simulator (CJES) was designed for jet noise, a Broadband Fan Engine Simulator (BENS) for the broadband component of turbomachinery noise, and a third engine noise simulator called the Ultrasonic Configurable Fan Noise Simulator (UCFANS) for the simulation of the tonal components of turbomachinery noise. Only the CJES and BENS were used in the HWB aeroacoustics test. The UCFANS was tested at NASA Glenn Research Center ${ }^{19}$ to obtain additional tonal data required to completely assess HWB shielding effects.

\section{A. Broadband Engine Noise Simulator (BENS)}

Each BENS consisted of an internally open nacelle with a representative core structure, and three interchangeable rings of impinging air jets with isolated plenums (shown in Figure 3). Each jet noise source was formed by four coplanar tubes arranged in a cruciform planform. Air was supplied at $120 \mathrm{psig}$ to each plenum through 0.5" lines. Each nacelle is approximately 6" in diameter and 12" long. Each nacelle had removable (and aerodynamically shaped) inlet and outlet caps (shown in Figure 4). These caps were used separately to simulate either inlet or outlet noise radiation. Each BENS was also instrumented with 10 unsteady surface pressure sensors distributed around the nacelle inlet and 10 sensors distributed around the core structure near the outlet.

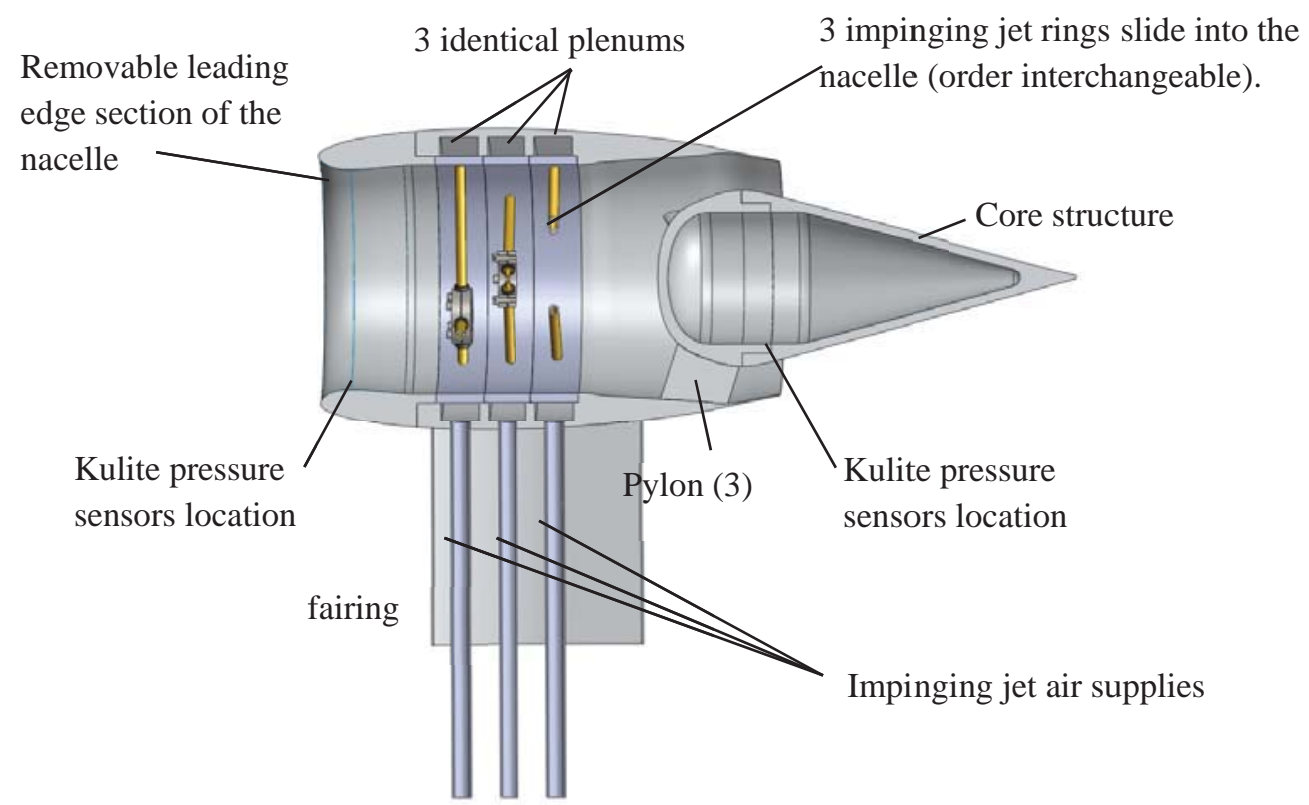

Figure 3. Cross Section of Broadband Engine Noise Simulator. 


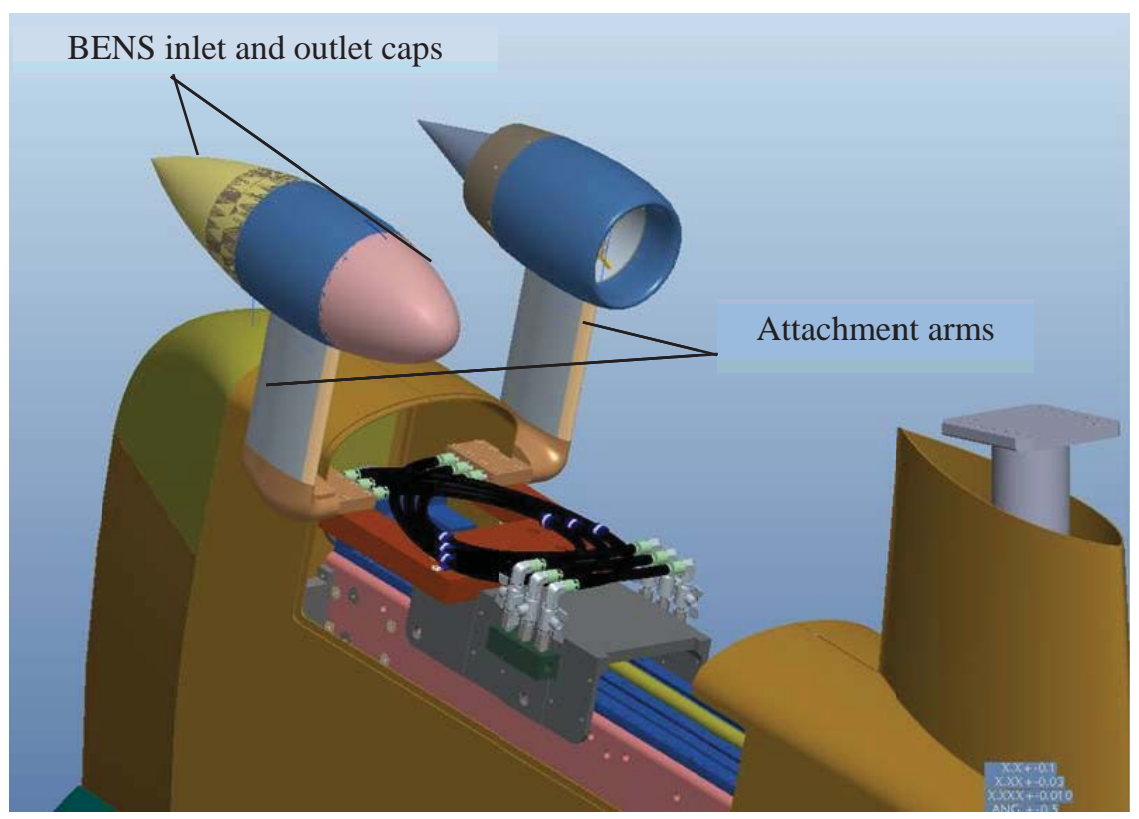

Figure 4. BENS Assembly on the Acoustic Model Support.

A series of preliminary tests were performed on the BENS to: (1) establish the BENS operating parameters (such as the impinging jets configuration, air pressure and transitional flow requirements); (2) establish the methodology to be used to analyze the BENS acoustic data; (3) determine the BENS noise radiation characteristics; (4) identify the parameters and signals that needed to be monitored during the HWB aeroacoustic test; and (5) guide the development of the HWB test matrix.

Testing of the BENS in a shielded configuration is shown in Figure 5. This particular test was performed to establish some of the BENS operating requirements and to exercise the data acquisition system that was developed to record the signals from the BENS unsteady surface pressure sensors and from the phased acoustic array, as well as to control the instrumentation traverse system.

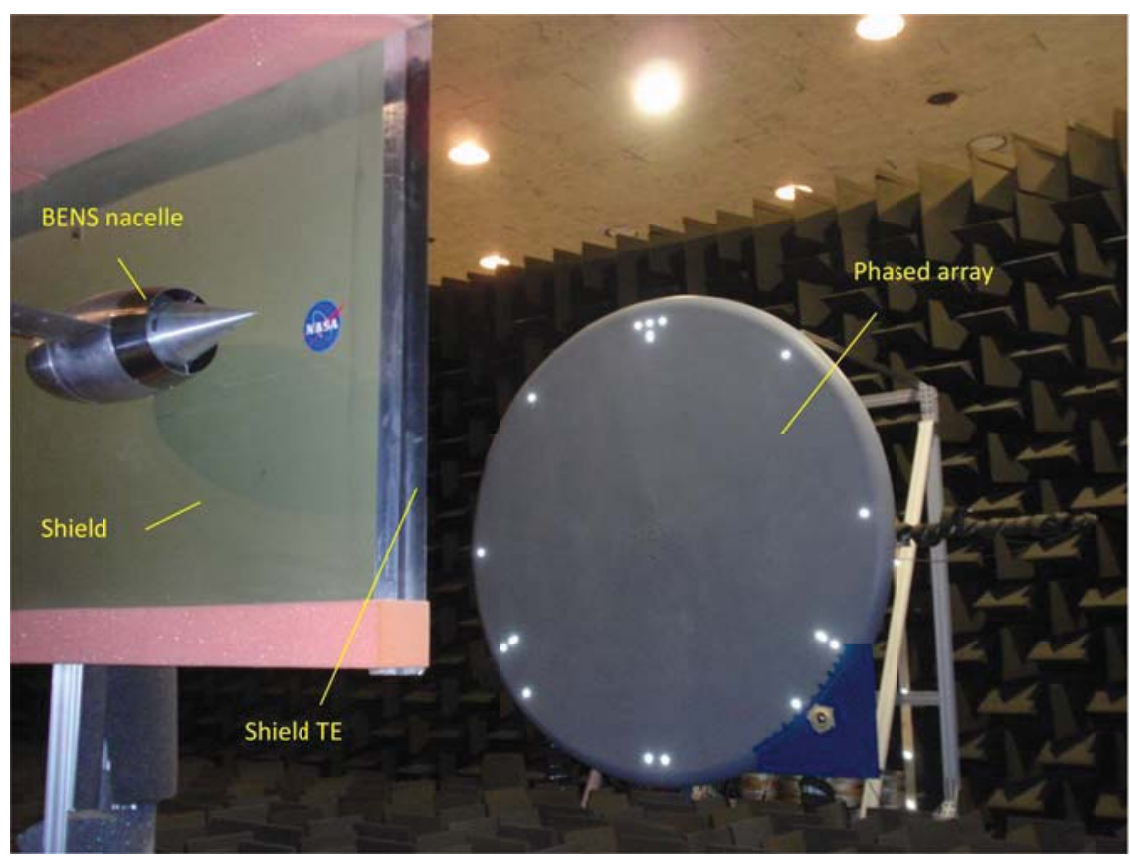

Figure 5. BENS Preliminary Shielding Test in separate Semi-Anechoic Facility. 


\section{B. Ultrasonic Configurable Fan Noise Simulator (UCFANS)}

The Ultrasonic Configurable Fan Noise Simulator (UCFANS) ${ }^{19}$ was designed, built and tested at NASA Glenn Research Center in the Acoustical Testing Laboratory (ATL). The UCFANS is a 5.8\% rapid prototype scale model of a high-bypass turbofan engine that can generate tonal signatures using artificial sources (no flow). Spinning modes (such as those produced by the engine's turbomachinery) are generated by an array of 36 wide-band electrostatic actuators inside a dual annulus within the fan duct and can drive modally phased tone signals between 7 and $40 \mathrm{kHz}$. The UCFANS was used to simulate the radiation of some of the HWB engine modes. Noise measurements from the UCFANS in shielded and unshielded configurations were obtained ${ }^{15}$. This data is to be used in conjunction with the BENS data acquired in the HWB aeroacoustics test to assess shielding effects on turbomachinery noise.

\section{Compact Jet Engine Sumilator (CJES)}

The jet noise source is produced by two dual stream jet engine simulators consisting of an interior heated core flow and outer fan flow. A fuel system, to be described later, supplies gaseous propane to a combustor in the core flow. The air and fuel flows for each engine simulator are independently controlled by two valve pallets.

The combustor concept for CJES was modeled after research done at the Air Force Research Laboratory $(\mathrm{AFRL})^{20}$. The combustor uses a unique compact annular propane burner to heat the core flow. The propane is burned in an annular combustion chamber followed by a core vane assembly which helps to straighten out the flow. A schematic of the jet engine simulator is shown below in Figure 6. The combustor injects fuel radially into a swirl cavity at 6 locations. Swirl air is injected on either side of the fuel jets angled at $45^{\circ}$ to radial and promotes mixing of the fuel and air. This design allows a shorter combustor length and a more efficient combustor.

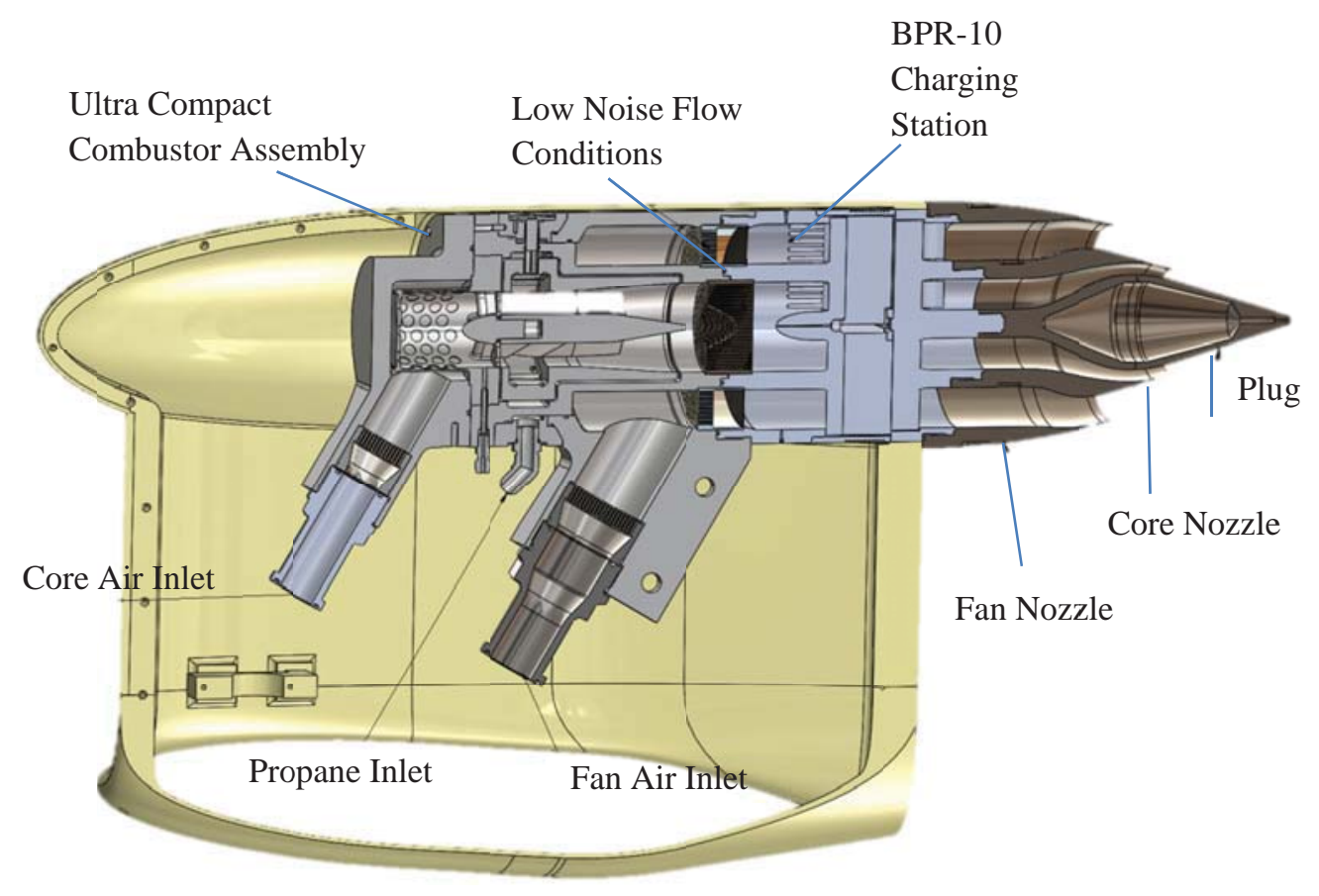

Figure 6. Compact Jet Engine Simulator Schematic.

The internal hot gas path components include a combustor liner and a core vane assembly. Laser sintered cobalt chrome parts were used for both the liners and the core vanes during the test to maximize durability.

The CJES nozzles to be used during the HWB test were sized to simulate a BPR of 10 engine, however, the fuel and ancillary systems (such as valve pallets) were designed to accommodate a broader range of bypass ratio (BPR) engine, between BPR-5 and BPR-15. Engine cycles and corresponding parameters (mach number-M\#, nozzle pressure ratio-NPR, and nozzle temperature ratio-NTR) were predicted based upon engine state tables provided by Numerical Propulsion System Simulation (NPSS) analysis for a bypass nozzle exit area of 4470 in $^{2}\left(15.12 \mathrm{in}^{2}\right.$ model scale) and consistent with each CJES nozzle design ${ }^{21,22}$. The given HWB flight profile and the NPSS engine deck for the cycle points were established for relevant HWB flight speed, altitude, and throttle settings. The CJES units, 
propane system and valve pallet assemblies operating at bypass ratios between BPR-5 and BPR15 yield the fuel and air supply requirements in Table 1.

Table 1. Supply requirements for the fuel and air systems.

\begin{tabular}{|l|l|l|l|l|l|}
\hline Bypass Ratio & Fuel flow & $\begin{array}{l}\text { Core Air Mass } \\
\text { Flow }(\# / \mathrm{sec})\end{array}$ & Temp $\left({ }^{\circ} \mathrm{F}\right)$ & $\begin{array}{l}\text { Fan Air Mass } \\
\text { Flow }(\# / \mathrm{sec})\end{array}$ & Temp $\left({ }^{\circ} \mathrm{F}\right)$ \\
\hline BPR-5 & $\begin{array}{l}50(\# / \mathrm{hr}) \\
(12 \text { gallons/hr) }\end{array}$ & 1.2 & 1250 & 5.8 & 150 \\
\hline BPR-15 & $\begin{array}{l}35(\# / \mathrm{hr}) \\
(8 \text { gallons/hr })\end{array}$ & 0.8 & 960 & 12.3 & 90 \\
\hline
\end{tabular}

The CJES nozzle components were designed to allow future nozzle interchangeability. Two BPR-10 nozzles, a baseline standard nozzle and a low noise chevron nozzle were tested in the 14x22 HWB test.

The low noise chevron nozzle design was the result of a test that took place at Boeing's Low-Speed Aeroacoustic Facility (LSAF) Tunnel ${ }^{23}$ which investigated several chevron and pylon designs at BPR 10 for both isolated (jet only) and installed (jet with partial airframe) configurations. One chevron nozzle (designated the "F8" nozzle) was selected as the best low noise nozzle. This chevron nozzle includes a T-fan chevron oriented with the longer chevrons in an asymmetrical pattern away from the airframe and ground observer locations, and a core chevron that is essentially a uniform design circumferentially. Since the LSAF test used a slightly larger scale than the HWB test, two 5.8\% scale, BPR-10, low noise nozzles were subsequently fabricated for use on the Compact Jet Engine Simulators.

The F8 low noise nozzle is shown in Figure 7, and the standard baseline nozzles installed on the CJES units are shown in Figure 8.
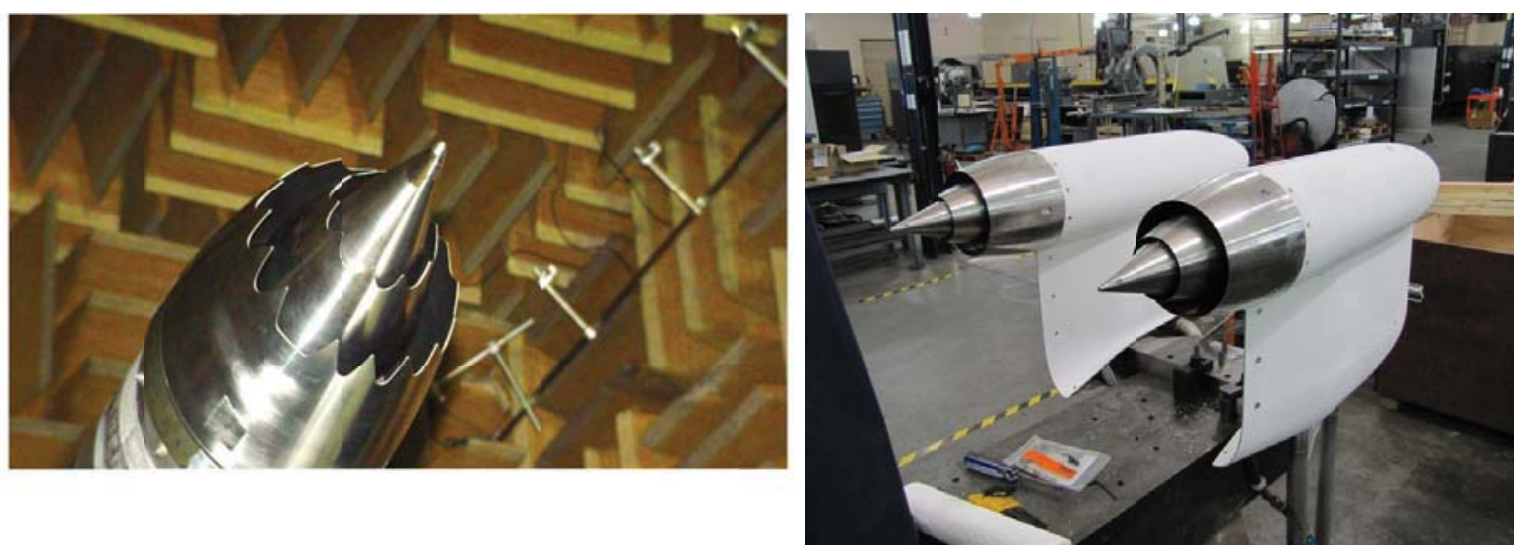

Figure 7. "F8" low-noise chevron nozzle in Boeing's LSAF Tunnel.

Figure 8. Baseline nozzle installed on the Compact Jet Engine Simulator.

The CJES is equipped with both pressure and temperature instrumentation. Nineteen (19) total pressure probes measure the pressure distribution of the instrumented charging station just upstream of the nozzle mounting features. The core stream has 9 total pressure probes mounted on two of the struts, one on the centerline and the remaining four distributed in an equal area pattern. The fan flow has ten (10) total pressure ports in an equal area distribution along two struts. There are also two static pressure ports in both the core flow and the fan flow and one (1) pressure measurement in the core plenum main cavity just upstream of the combustor ring. To measure the CJES gas temperatures, eighteen (18) type K thermocouples measure the nozzle temperature distribution of the instrumented charging station just upstream of the nozzle mounting features. The core stream has eight (8) thermocouples distributed in an equal area pattern matching the pressure probes. These eight thermocouples were monitored to verify the burner ignition as well as the burner operating conditions. The fan stream has ten (10) thermocouples in an equal area pattern matching the pressure probes.

The CJES operation can be controlled either manually or automatically by a Programmable Logic Controller (PLC). The PLC controls the propane mass flow and core and fan air flows, and monitors the core and fan flow 
stream temperatures and pressures. Once the mass flows were set to the correct range, fine control adjustments were based on nozzle temperature ratios (NTRs) and nozzle pressure ratios (NPRs).

Numerous CJES risk reduction studies were completed in preparation for the HWB acoustic test. A brief overview of each study and an explanation of their relevance to the larger HWB test are given below.

Operational and preliminary acoustic testing took place in NASA's Low Speed Aeroacoustic Wind Tunnel (LSAWT) which was modified to accommodate the CJES fuel valve pallet. Establishing consistent operation of each of the CJES units was a primary objective. This objective was achieved in the LSAWT after several modifications to the combustor and core flow conditioners ${ }^{24}$ (see Figure 10).

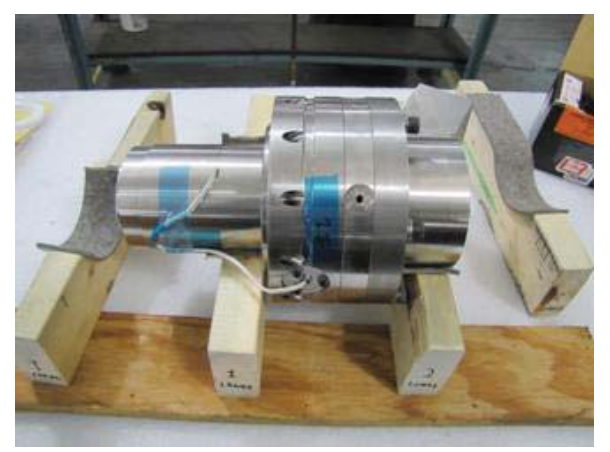

Figure 9. Ultra Compact Combustor for CJES unit. The core air flow enters from the right. Propane combustion is contained in the mid annular section. The fuel and bypass air ports are located circumferentially around the annular combustion section.

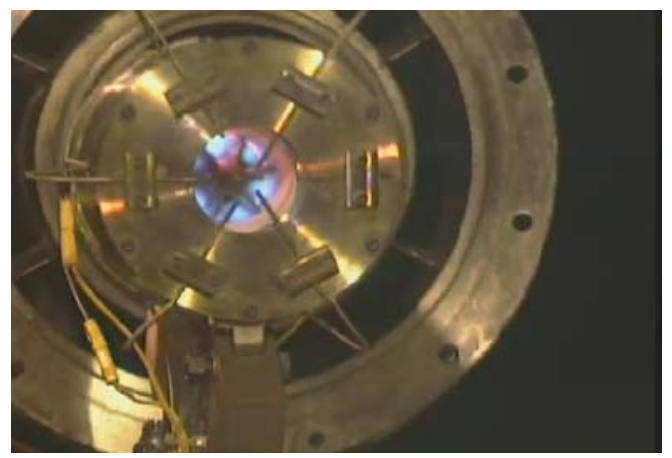

Figure 10. Assembled CJES unit shows proper CJES operation with the flame controlled in the upstream annular flow cavity of enclosed combustor.

One challenge in modeling scaled jet noise is that internal rig noise tends to contaminate the jet noise. Flow conditioner studies by Doty and Haskin ${ }^{25}$ investigated the acoustic properties of numerous flow conditioner configurations for optimal rig noise reduction in anticipation of this issue. Flow conditioners and screens were evaluated to help minimize unwanted tones and broadband noise.

In addition to understanding each CJES unit individually, relevant twin jet acoustic and flow field effects were investigated by Doty ${ }^{26}$ in the LSAWT using the linear microphone array and the Jet Noise Directional Array $\left(\mathrm{JEDA}^{27}\right)$. Recommendations for the CJES test matrix based on twin jet results were used as input for the HWB test matrix.

\section{Facility Description}

The 14 by 22 Foot Subsonic Tunnel ${ }^{28}$ is a closed-circuit, single return, atmospheric wind tunnel with a 12,000 HP drive capable of producing a maximum speed of 348 feet per second (Mach 0 to 0.3), and Reynolds Numbers between 0 and $2.2 \times 10^{6}$ per foot. The cross section of the test section inlet measures $14.5^{\prime} \mathrm{H}$ x 21.75' $\mathrm{W}$ x 50' L. The facility can be operated in either an open (floor only) or a closed test-section configuration. The test section was in the open configuration for the acoustic test and in the closed configuration for the aerodynamic test. A sketch showing the details of the complete tunnel circuit is presented in Figure 11.

Two major tunnel improvements were made to provide NASA researchers the ability to test the HWB model at realistic flight conditions. A traversing mechanism was added to allow the positioning of a phased microphone array to remain outside of the tunnel shear layer in the open tunnel configuration, and a fuel delivery system was added to supply propane to the CJES combustor core streams to properly represent high gas temperature engine noise characteristics.

In addition to these major facility improvements, several other tasks were completed to enhance the acoustic characteristics in the $14 \times 22$ Tunnel: A portion of the control room wall was moved 7 feet away from the test section. This was done so that microphone towers and side rails could be placed outside of the tunnel shear layer flow for the entire length of the test section. Moving this wall also benefited the tunnel aerodynamics by removing a potential source of flow skew in the open section flow; Cable conduits connecting the control room to a patch panel on the far side of the tunnel were installed to manage cabling and ease test setup time. Acoustic treatment was modified to account for tunnel modifications. Foam wedges were installed on the new blast wall as well as the new ceiling 
panels built to fit between the traverse and the test section ceiling; A secondary photogrammetric measuring system was installed to positively locate the overhead traverse in tunnel coordinates. And finally, a data acquisition system was developed to manage the HWB data.

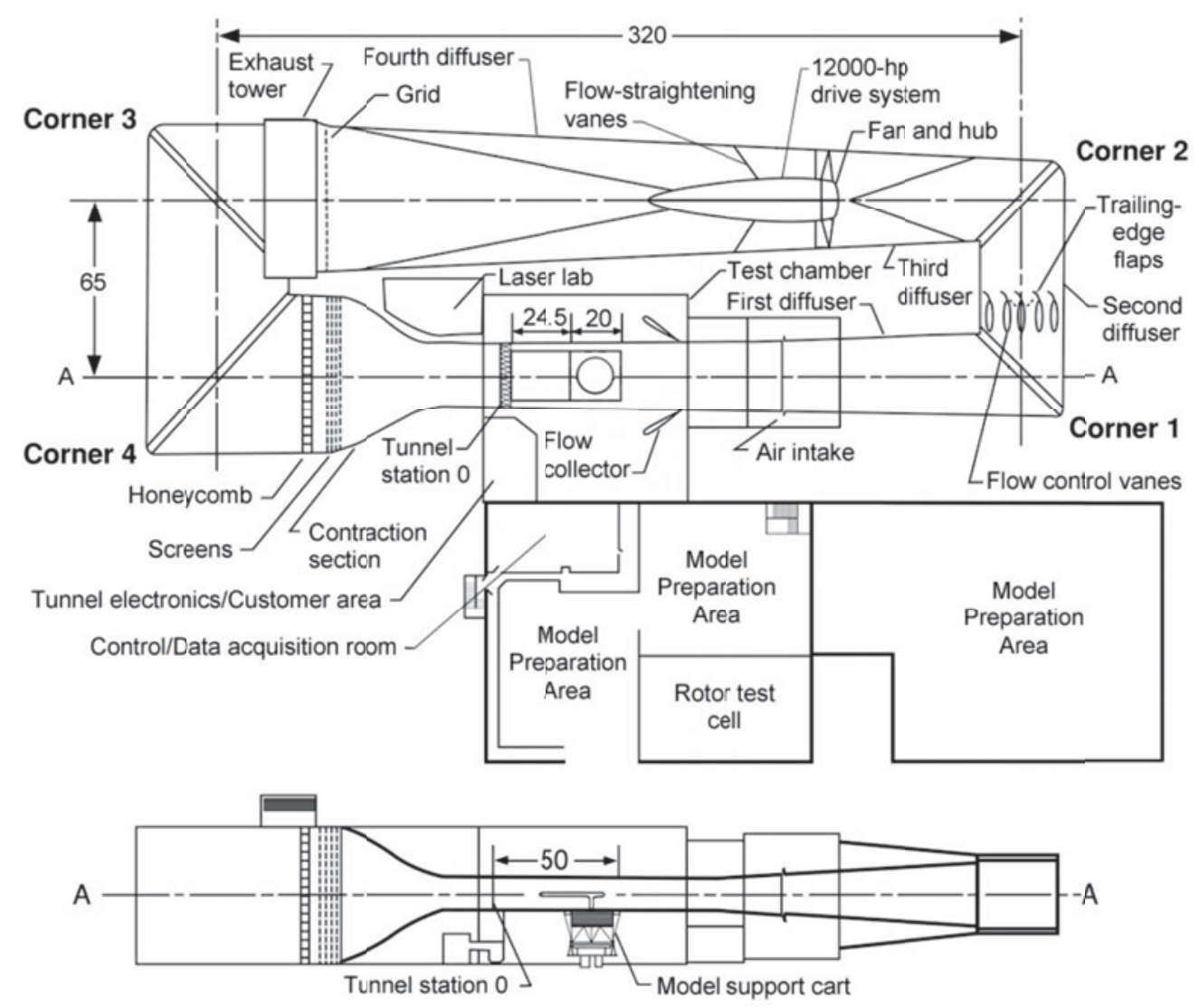

Figure 11. NASA Langley 14 by 22 Foot Subsonic Tunnel Circuit. Dimensions are given in feet.

\section{A. Overhead Traverse Mechanism for Array Panel}

An overhead mechanism was designed and fabricated to position an acoustic phased array within the test section. The rectangular truss structure was mounted between the two reinforced facility crane rails as shown in Figure 12. The mechanism includes both the hardware and software sub-systems required to position a 350 pound array longitudinally and laterally over the entire length and width of the test section from the tunnel flow entry to the leading edge of the flow collector. It also includes cable support carriages to manage the phased array instrumentation and power cables as the array moves side to side and is raised and lowered to floor level for access to instrumentation mounted on the array panel. The traversing mechanism has a longitudinal and lateral translation speed of four (4) inches per second with lateral and longitudinal positioning accuracies below \pm 0.125 " and \pm 0.5 " of the commanded absolute location respectively with wind off. The traverse structure was designed to minimize array rotations and deflections under expected tunnel vibration.

Both the tunnel crane and the overhead traversing mechanism operate independently on the same longitudinal tunnel rails. Since only one can use the rails at a time, a storage compartment was constructed to store the overhead traverse over top of the inlet lip of the tunnel while the crane is in use. 


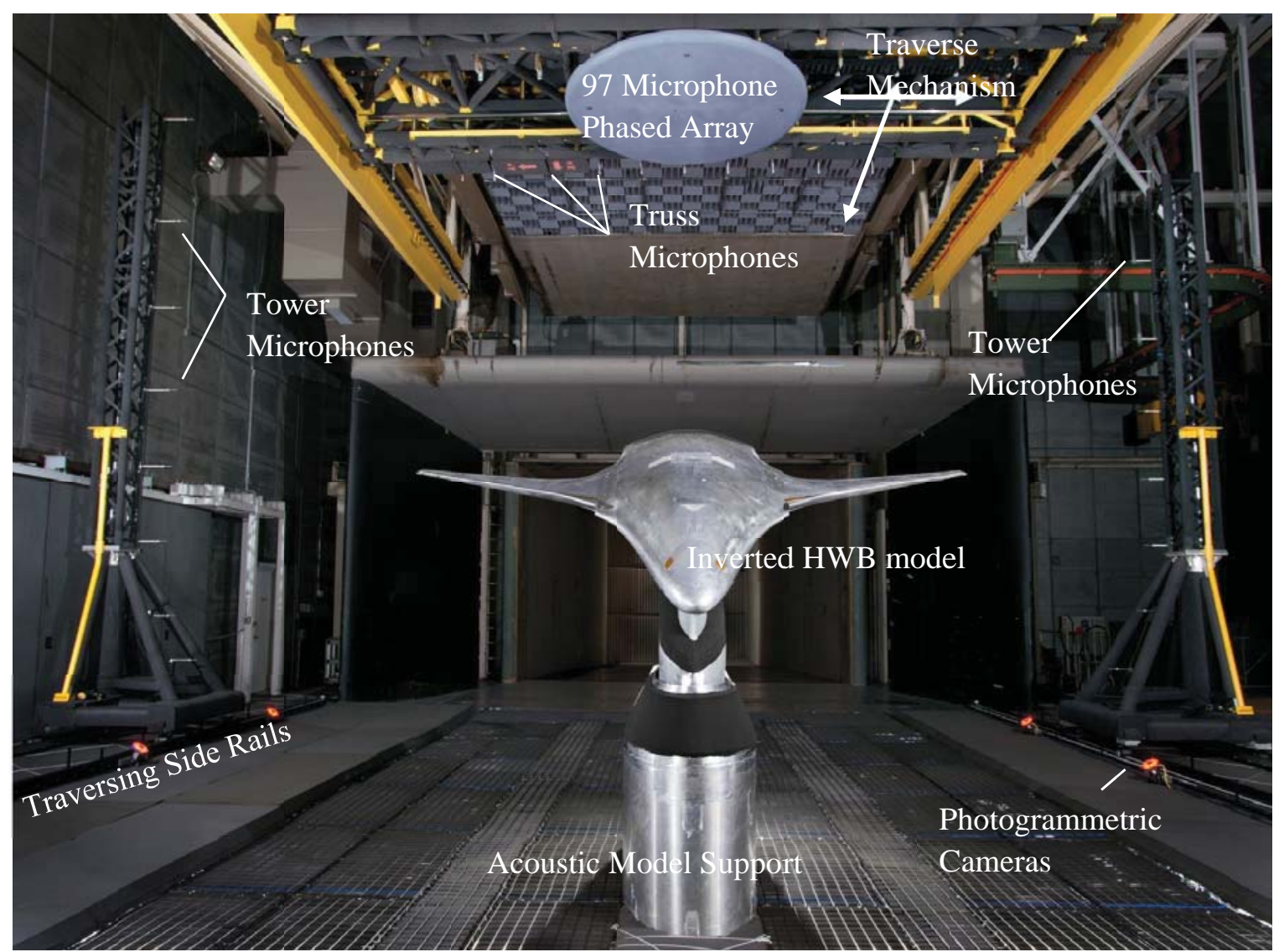

Figure 12. HWB test section configuration. Photograph by George Holmich.

\section{B. Microphone Towers}

Two 11 foot tall open truss vertical sideline towers were constructed to support individual microphones in order to measure hemispherical characterizations of noise directivity for various model configurations. The two sideline towers were mounted on top of two sets of 40-foot floor mounted linear traversing rails which were installed on either side of the test section as shown in Figure 12. The tower structure is located outside of the tunnel shear layer and is designed to minimize vibration, especially below $15 \mathrm{~Hz}$ which might resonate at normal tunnel operating frequencies. The two rail systems were synchronized with the overhead traverse structure such that all microphones moved together in the streamwise direction. Twenty nine microphones were arranged radially about the model center of gravity spaced nominally at 7.5 degree increments and were held in place by 12 to 14 inch horizontal support tubes extended from the tower and truss structures in a direction perpendicular to the flow. An adapter made from electrically non-conductive material held the microphone preamps in the supports. Further microphone details are discussed later in the Acoustic Instrumentation and Data Acquisition Section.

\section{Facility Acoustic Treatment}

The facility is acoustically treated to minimize acoustic reflections. The main tunnel walls and diffuser have perforated plates that cover most of the facility. In addition to these plates, the floor, ceiling and blast wall have been treated with $2 \mathrm{lb} / \mathrm{ft}^{3}$ acoustic foam wedges. The model carts were recessed two feet and foam filled baskets were placed in the space to acoustically treat the test section floor. The foam baskets consist of alternating low $\left(2 \mathrm{lb} / \mathrm{ft}^{3}\right)$ and high $\left(6 \mathrm{lb} / \mathrm{ft}^{3}\right)$ density acoustic foam wedges, covered with a less dense foam covering. The baskets and retaining hardware are designed to allow smooth air flow so as not to disrupt the tunnel aerodynamics 
The wedges on the ceiling are 6 inches thick in order to fit between the ceiling and the overhead traverse. Wedges on the blast wall were constructed of the same foam as the ceiling but had an additional open spacing behind the mounting plates to further damp reflections. The wedges for the ceiling and blast wall are shown in Figure 13

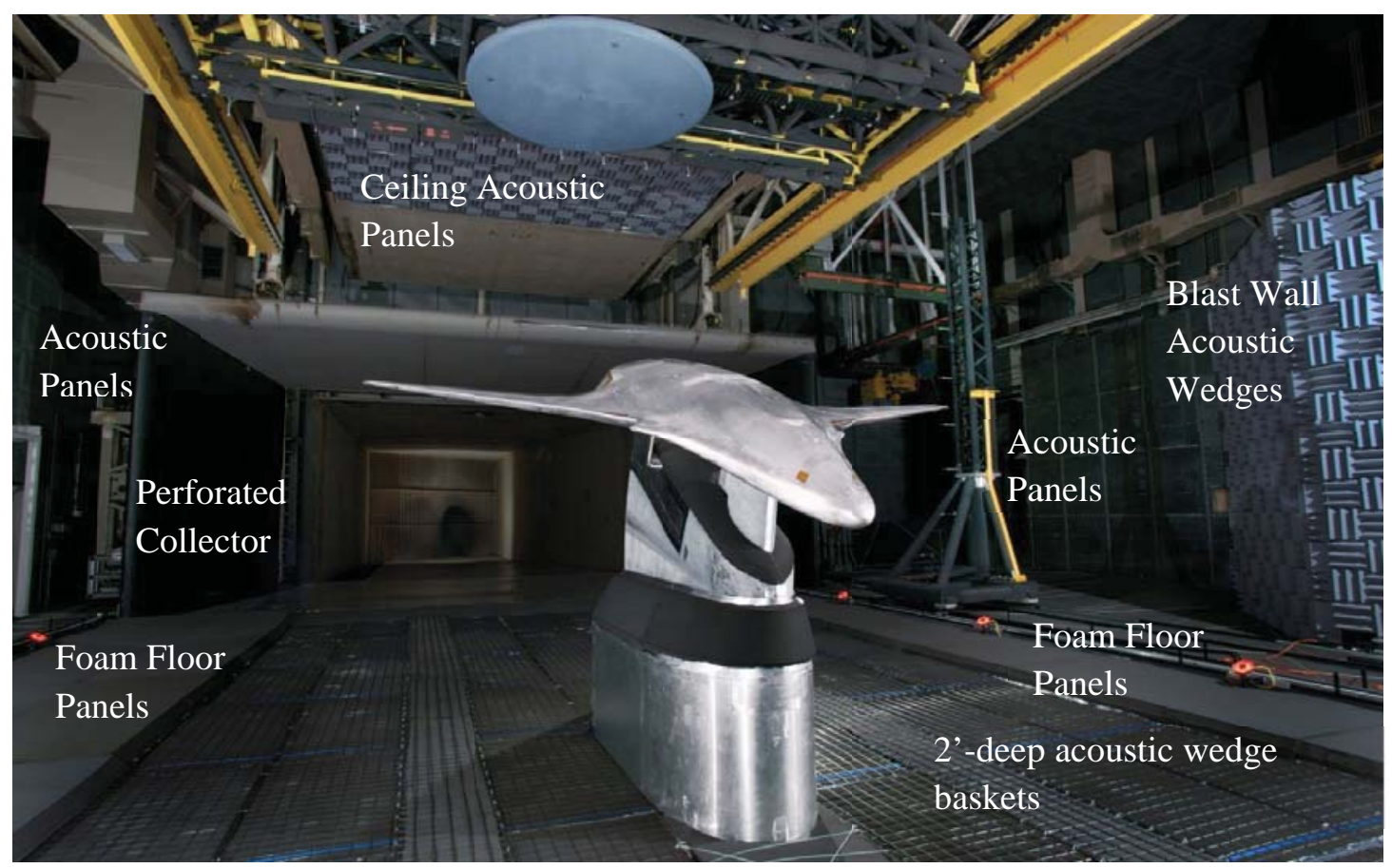

Figure 13. 14x22 Tunnel Acoustic Treatment. Photograph by George Holmich.

\section{Photogrammetric Measurement System}

A photogrammetric measurement system was installed to provide a secondary measurement of the microphone array location. The primary traverse location and control is provided by the traverse drive encoder. The photogrammetric tracking system was created using commercial off the shelf hardware and custom software to handle image capture and processing. The video capture component of the system comprises eight cameras fitted with $5 \mathrm{~mm}$ lenses. The cameras have a 5 megapixel CMOS sensor with a resolution of 2560 by 1920 pixels, resulting in a field of view of approximately 90 degrees, and a maximum 14 frames per second capture rate. The cameras are operated in a synchronized mode using a separate set of trigger cables connected to a programmable controller.

The operation of the system requires retro-reflective targets to be placed on reference locations within the wind tunnel and on the model to be tracked. The reference targets are used to determine the position and orientation of each camera. The targets are illuminated using LED ring lights on each camera. To further isolate the targets from ambient light sources and reflections, narrow wavelength red LEDs are used in conjunction with filters on the camera lenses. The tracked targets are located in 3D space with respect to the tunnel coordinate system using intersections and an automatic correspondence algorithm to identify matching images for each camera. In each case a robust least squares estimation solution is used to detect and eliminate errors in the measurements to ensure a robust and accurate solution. Typical precisions (one sigma) of the location and orientation angles of the array are \pm .04 inches and \pm 0.05 degrees respectively.

\section{E. Facility Fuel System}

A fuel system and outside test stand were designed and built for this experiment to supply propane to the jet noise simulator core. Portable valve pallets and a Programmable Logic Controller (PLC) control the engine operations within the $14 \times 22$ Tunnel infrastructures. The outside testing capability is beneficial for both debugging the systems as well as training personnel on the operation of the fuels system. 
The fuel supply system consists of propane fuel and nitrogen systems, where nitrogen is used for pressurization and purging. During the purge operations the system has the capability to force remaining propane in the run tank back to the storage tank.

The liquid propane is stored in a 2500 gallon storage tank and is pumped into a 500 gallon run tank. An electric vaporizer converts the liquid propane to gaseous propane. A manifold located downstream of the vaporizer distributes the gaseous propane to the CJES valve pallets when needed. The storage and run tanks are shown in Figure 14
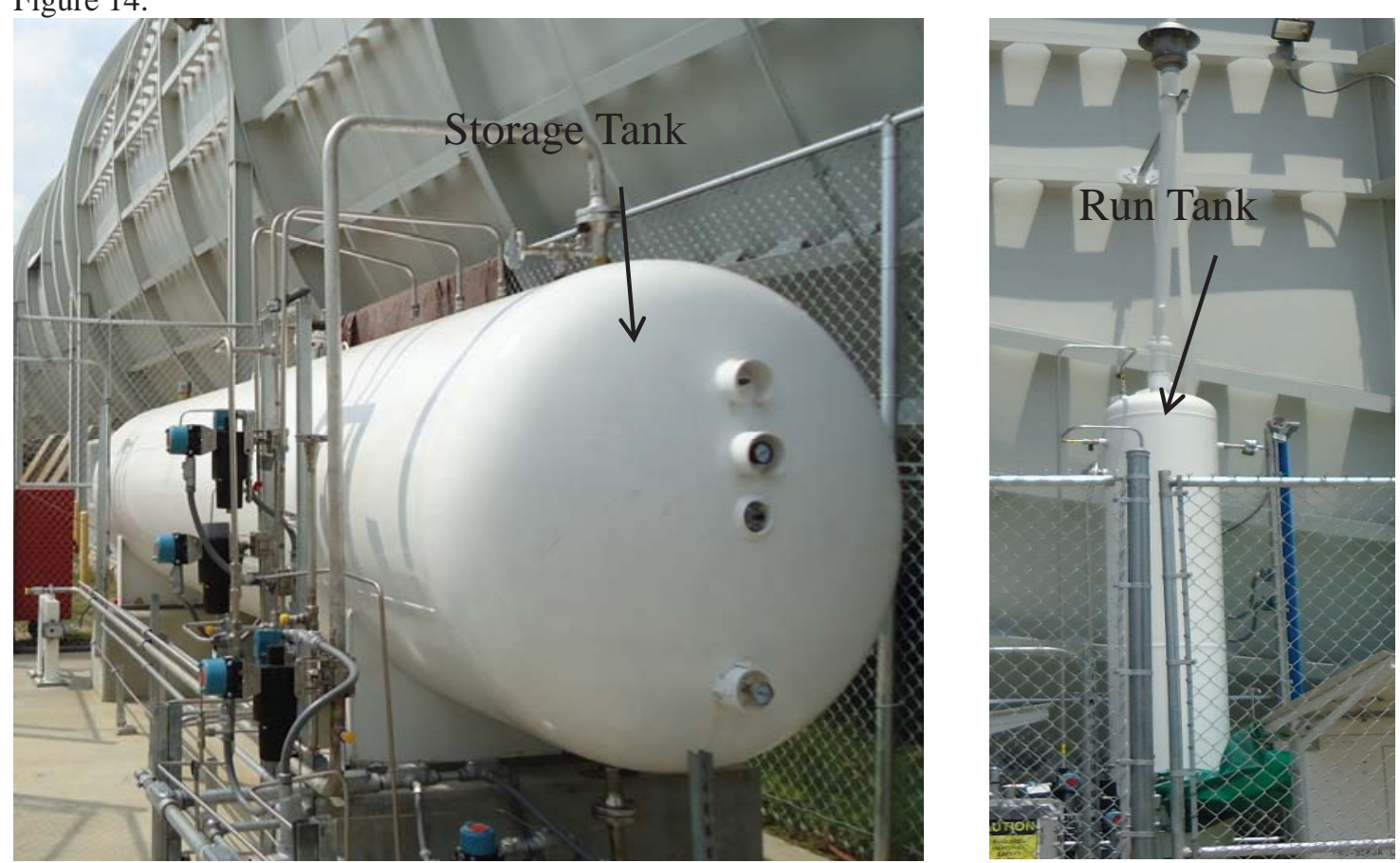

Figure 14. 2500 gallon liquid propane storage tank and 500 gallon run tank. An electric pump transfers liquid propane from the storage tank to the run tank.

There is one valve pallet for each Compact Jet Engine Simulator (CJES) unit. The intrinsically safe control cabinet can be seen on the left of the valve pallet in Figure 15. The main purpose of the valve pallets is to control the nitrogen, propane and air operations ${ }^{29}$. All valve pallet operations are commanded and monitored using the PLC. The valve pallets supply one fuel line and two air lines, one for the fan flow and one for the core flow, to each CJES unit. the portable valve pallet with sealed tank open at the outside test stand are also seen in Figure 15. 


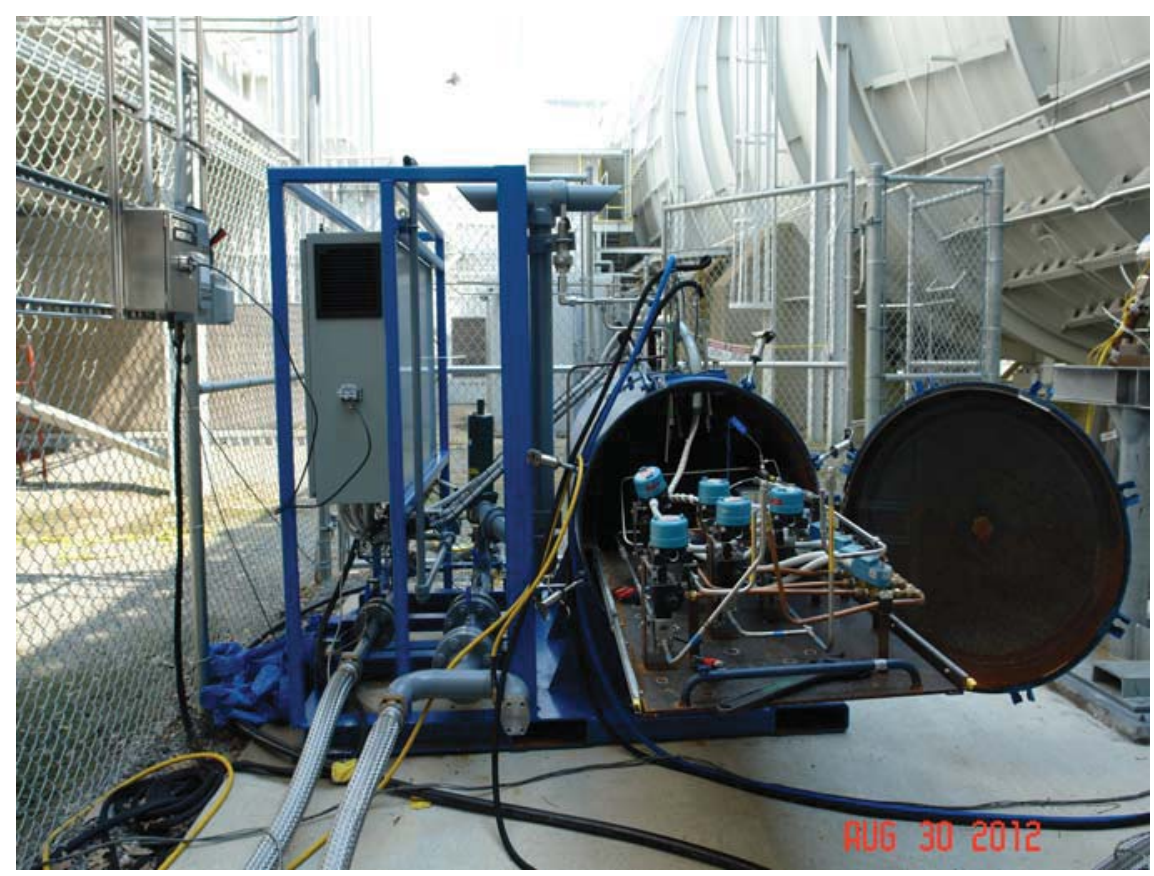

Figure 15. One of the two portable valve pallets with sealed tank open at the outside test stand. The intrinsically safe control cabinet is shown on the left.

\section{Miscellaneous Facility Studies}

Several preliminary risk reduction wind tunnel studies, some large - some small, were completed prior to building the test matrix. These studies include risk reduction efforts to mitigate unforeseen events, as well as setting operational limits, testing parameters and acoustic measurement conditions. Studies included tunnel vibrations and natural frequency studies for array and structural response requirements, open and closed aerodynamic tunnel wall influence studies including model roll effects, tunnel temperature studies to determine acceptable weather conditions for testing, and tunnel background noise studies, both before and after testing, to define the facility acoustics with respect to other acoustic tunnels and to assess instrumentation range requirements.

\section{Model Support Systems}

Due to the large model size and corresponding high aerodynamic loads, two completely new model support systems were designed and built for the aerodynamic and acoustic tests. The aerodynamic test was performed with the model upright and flow through nacelles attached to the model with pylons. During the acoustic test, in order to capture the full acoustic shielding effects of the HWB model for ground observers, the model was mounted upside down so that overhead phased microphone array and individual microphones could traverse over the model. The two fully assembled configurations are shown in Figures 16 and 17 below.

Both aerodynamic and acoustic model support systems are mounted on existing model carts and are controlled by the facility control system. The aerodynamic model support system entered the bottom of the HWB model and was designed to locate the model on the tunnel centerline during angle-of-attack and sideslip sweeps.

During the acoustic test, the inverted HWB model was mounted on a stationary strut. The strut was separated to allow the pitching and rolling mechanisms to be independent. The top of the strut connected the model to the pitch mechanism and also supported an attachment arm to mount the engine simulators. The lower portion connected the pitch and roll joints.

The pitch mechanism provided variation in angle of attack (AOA) and was controlled by the facility's control and data acquisition systems. With the model at $10^{\circ}$ angle of attack, the pitch mechanism was at the center of its travel and the post was vertical. The required range in this configuration is $+25^{\circ}$ to $-5^{\circ}$ as shown in Figure 18 . 


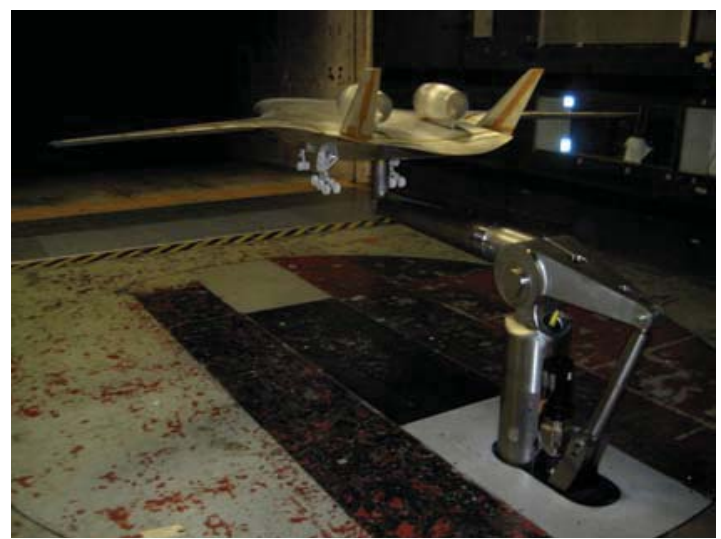

Figure 16. The $5.8 \%$ HWB model mounted on the aerodynamic support system installed on model cart \#1 in the 14x22 Tunnel. Photograph by George Holmich.

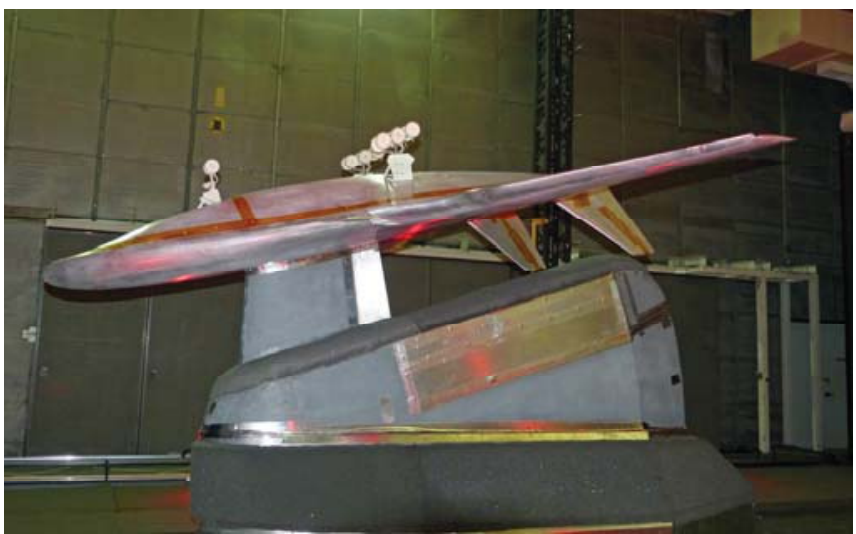

Figure 17. Acoustic model support with fairing and acoustic treatment applied. Photograph by George Holmich.

A roll knuckle located below the pitch mechanism allowed the model to be manually rolled and locked at $-30^{\circ}$, $0^{\circ}$, and $+30^{\circ}$. The roll knuckle is located below the pitch mechanism so that the model angle of attack can be set while the model is rolled without inducing a yaw angle.

The engines were mounted on the acoustic model support hardware in order to enable relative axial motion between the HWB model and the engine. The entire assembly (HWB and engine simulators) pitches and rolls together as one mechanism. The axial motion is aligned with the body centerline and contains a constant 5 degree offset angle between the simulators and the HWB centerline, which is the angle between the upper surface of the airplane and the body centerline.

Five (5) discrete longitudinal (or axial) locations are preset for the fan and jet simulators. The 5 locations, referenced to the nozzle exit plane with respect to the trailing edge, are $\mathrm{x} / \mathrm{D}=[3.0,2.5$ (baseline), 1.5, 0.0, and -0.5 ] where "D" refers to fan nozzle exit diameter and " $x$ " refers to axial distance from fan nozzle exit to trailing edge with positive values denoting a fan exit location upstream of the trailing edge over the body.

The model can be attached to the acoustic model support either with or without a balance. When no balance is used, the support is bolted directly to the model strong back. This direct connection was added to minimize modelengine interactions due to air loads or vibrations. Both connection blocks, one with and one without a balance in place, were fabricated for the HWB model and are interchangeable on the model support. The current acoustic test did not use a balance. It was mounted directly to the strong back using the appropriate mounting block.

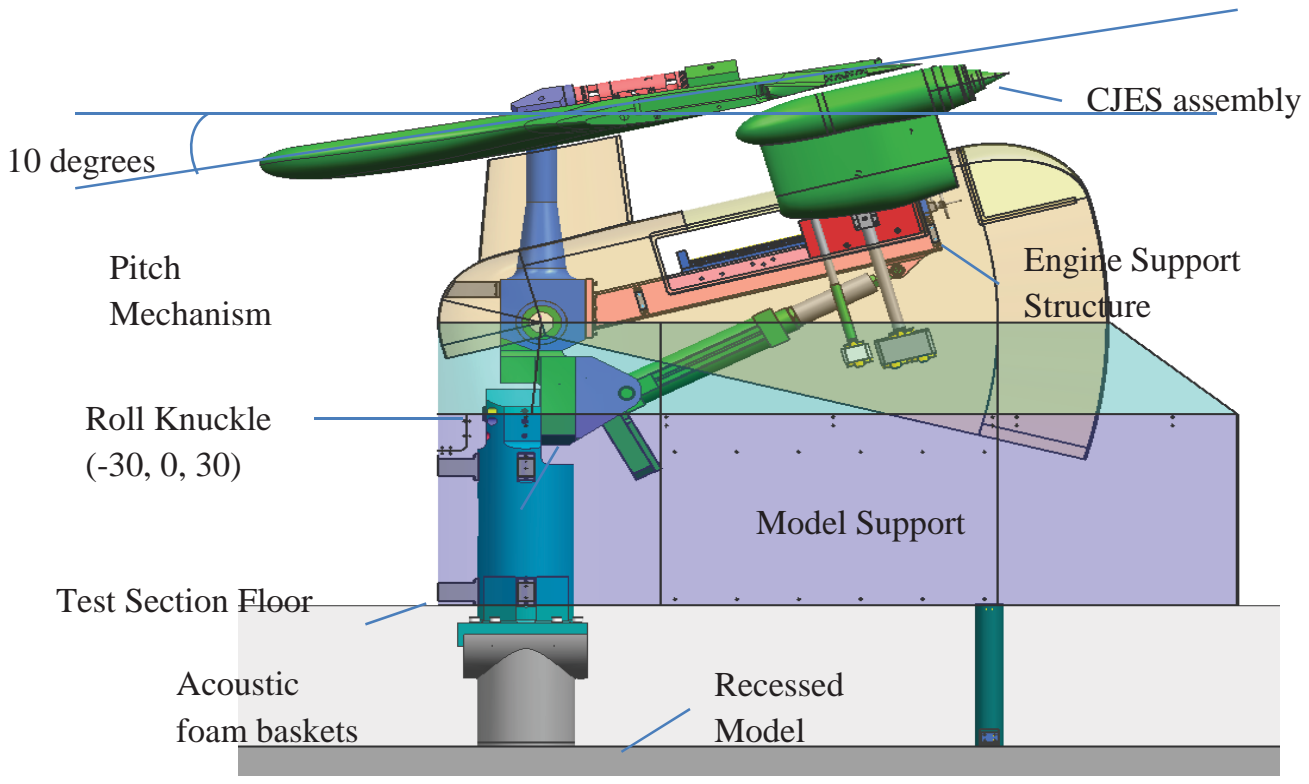

Figure 18. Acoustic Model Support 


\section{Acoustic Instrumentation and Data Acquisition}

A data acquisition system was developed to command and control of all aspects of the instrumentation and associated hardware for the HWB test. The system managed the instrumentation for the phased array microphones, sideline and truss microphones, and BENS pressure sensors. Specific details of the various subsystems comprising the instrument suite are described in this section.

\section{A. Data Acquisition System}

The distributed data acquisition system was assembled for this test using commercially available hardware. The entire data system was controlled from a master computer which communicated with the various digitizer clients using high speed ethernet communications, as shown in Figure 19. The data acquisition system had a capacity of 192 channels and was constructed around high speed, synchronous sampling digitizers. The digitizers were housed in three separate chassis each containing an embedded client computer with local disk storage. Signal conditioning of all microphone channels was achieved using precision filters.

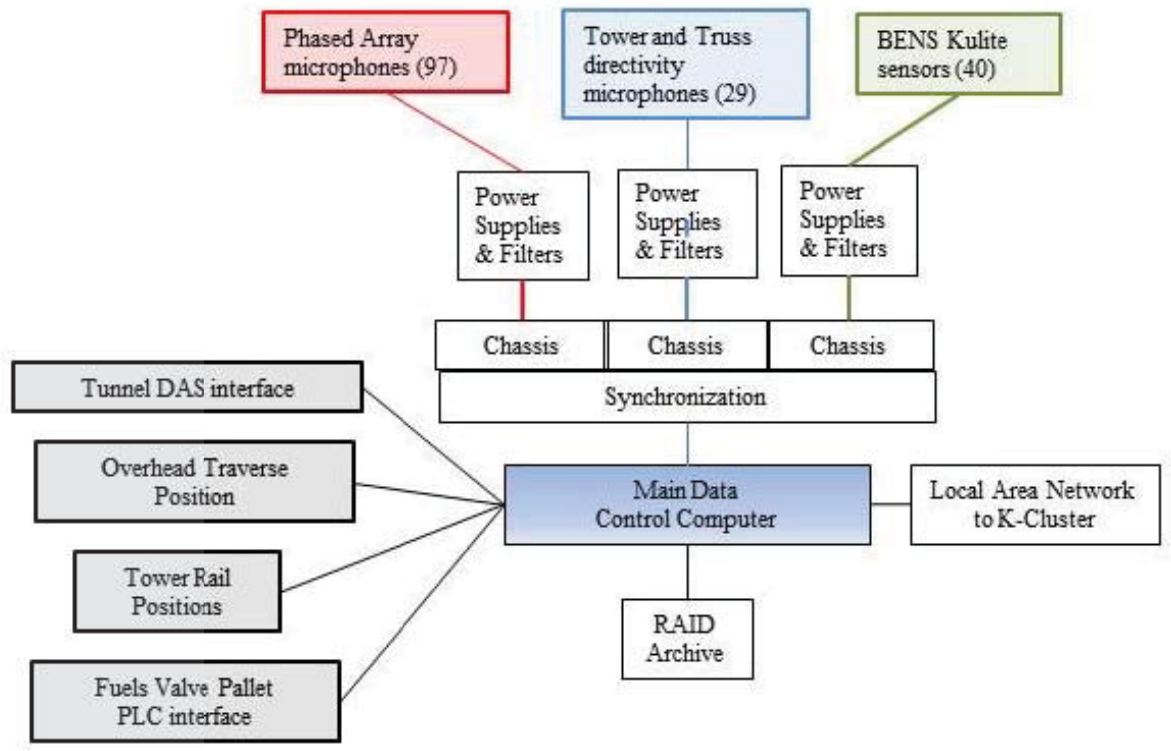

Figure 19. Data Acquisition Layout

The nominal simultaneous sampling rate for all channels was $250 \mathrm{kHz}$, with a high-pass filter cut-on frequency centered at $400 \mathrm{~Hz}$ and a low-pass filter cut-off frequency centered at $102 \mathrm{kHz}$. The large microphone time history data files were transferred to high capacity RAID (Redundant Array of Independent Disks) drives for storage. The main data control computer and acquisition system is shown in Figure 21.

In addition to gathering the microphone and pressure sensor data, the acquisition program commanded the desired locations of the overhead traverse system and the two side rail systems for the array and tower positions. The acquisition program also interfaced with the wind tunnel data system and fuels PLC to capture relevant tunnel and model parameters during each acquisition cycle.

\section{B. Microphone Phased Array}

A new microphone phased array design was constructed for the HWB test ${ }^{30,31}$ as shown in Figure 20. The array consisted of 97 1/4-inch pressure field microphones attached to 1/4-inch preamplifiers. The microphones were flush mounted, without any surface coverage gaps, in a flat fiberglass honeycomb plate with a total diameter of 8.05 feet. The array was designed for a frequency range of approximately $1.5 \mathrm{kHz}$ to $80 \mathrm{kHz}$. The microphones were powered by two separate power supplies, one for the inner 48 channels, a second for the outer microphones. All microphone signals were transmitted to the data acquisition system using microphone cables. 
The maximum aperture size (outermost microphone to outermost microphone) was 78.6 inches, yielding a solid collecting angle of 27 degrees for the lower frequencies at a working distance of 13 feet. For higher frequencies, the collecting angles are limited to smaller angles required by processing methods.

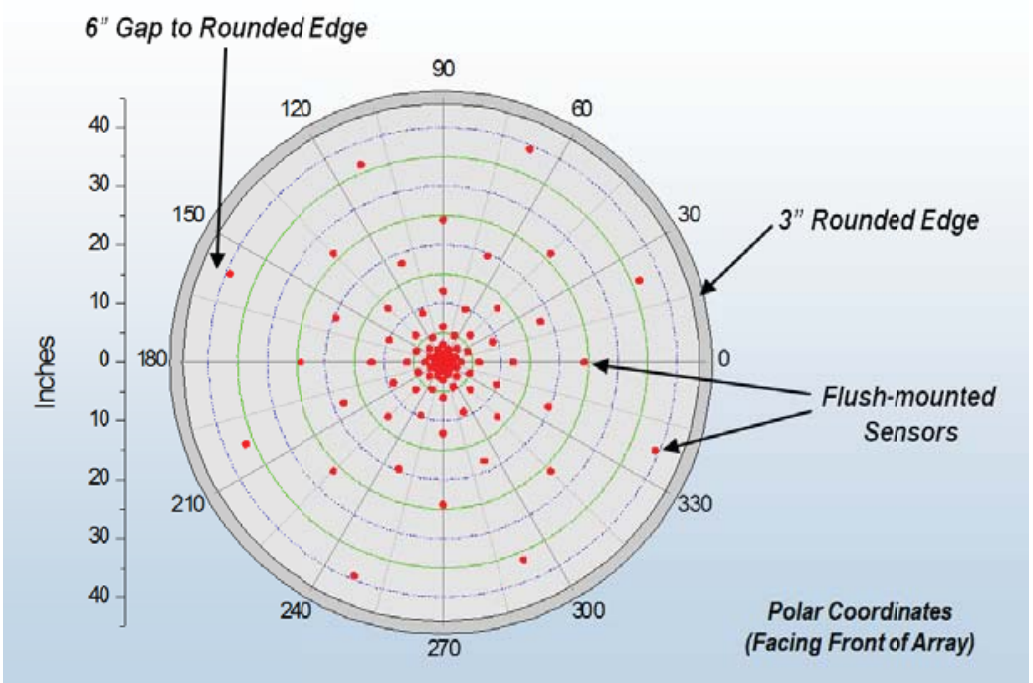

Figure 20. Phased Array. Irregular circular pattern of microphones is comprised of 16 array arms with 6 microphones in each arm, and one microphone positioned in the center of the array.

A customized integral accelerometer and inclinometer system was designed as part of the array panel for monitoring panel tilt and vibration during tunnel operation. The accelerometer / inclinometer sensors were controlled and digitized by an on-board microcontroller system located on the rear of the microphone array panel. The microcontroller transmitted the inclinometer data to the acquisition system using a standard Ethernet cable connection and the accelerometer data was supplied via an analog coaxial cable connection.

The array microphones were calibrated with pistonphones prior to testing and an in-situ calibration method during testing. The in-situ calibration method was performed daily using three embedded speakers which were mounted in the panel and activated in turn to track any drift in microphone sensitivities. Injection calibrations were also used periodically to track the microphone calibrations. These injection calibrations were completed by applying a broadband white noise signal with known RMS voltage to each preamplifier and recording the output signal.

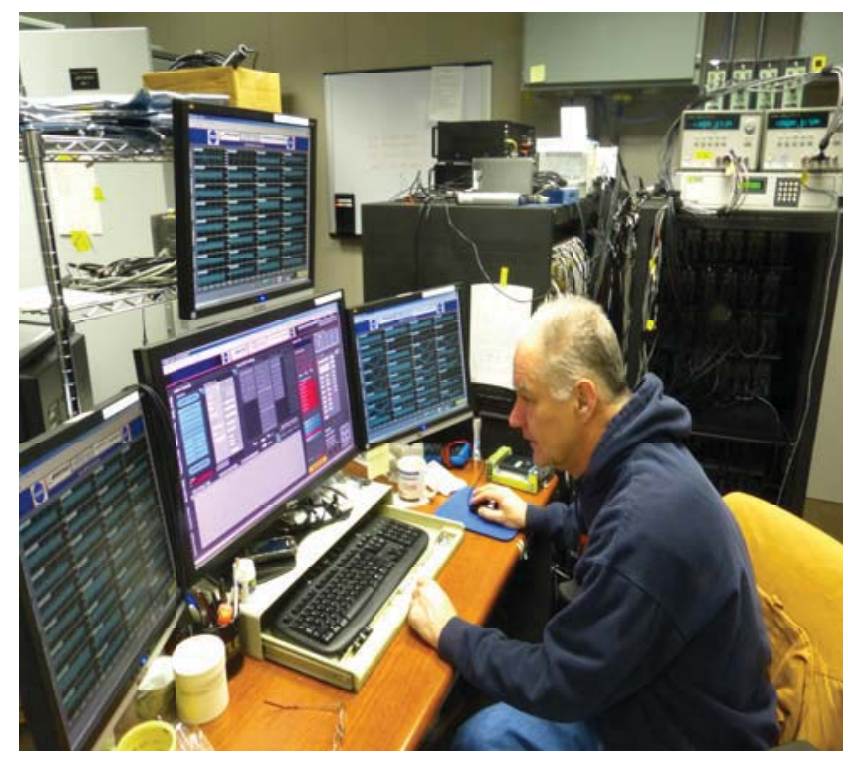

Figure 21. Data acquisition system main data control computer for the HWB Test. Four monitors are used to track acquired data streams during testing.

\section{Tower and Truss Microphones}

A series of 29 individual microphones were mounted around the facility test section on the sideline towers and overhead traverse truss for use in hemispherical characterizations of noise directivity for various model configurations as shown previously in Figure 12. The sensors were comprised of $1 / 8$-inch pressure field microphones attached to $1 / 4$-inch preamplifiers using $1 / 4$-inch to $1 / 8$-inch adapters. Microphone signals were 
transmitted to the data acquisition system using microphone cables and were powered by dual-channel conditioning power supplies.

During the HWB test, the microphones on the truss and towers were calibrated periodically using injection calibrations, in the same manner as the phased array microphones. Independent hand-held pistonphone calibrations were performed on the tower and truss microphones on a weekly basis.

\section{Data Reduction}

Microphone data was reduced and made available for review directly following each acquisition. The time history data also contained metadata regarding data acquisition settings and tunnel/model parameters. A series of "Quicklook" codes were created to review the individual auto spectra, cross spectra, and ordinary coherence between channels using known procedures ${ }^{32}$. Over-night detailed analyses of array data was transferred to the NASA Langley high performance mid-range computing resource referred to as "K Cluster" to perform standard frequency-domain delay and sum beamforming coupled with the DAMAS deconvolution algorithm for generation of final noise source map presentations ${ }^{33,34}$.

\section{Test Matrix}

The test was designed to obtain understanding of the independent aeroacoustic characteristics (jets, broadband turbomachinery and HWB model noise sources) as well as the effect of shielding. The HWB acoustic test was comprised of five parts: 1) Isolated BENS, 2) BENS and HWB airframe, 3) Isolated HWB airframe, 4) CJES and HWB airframe, and 5) testing to define acoustic facility properties. The duration of the test was 105 days which included the test section preparations and all required installations.

The acoustic test setup did not include a balance and hence the lift, drag and moment were not available directly but instead were made available from the aerodynamic test results ${ }^{3}$. These aero-performance measurements in terms of low speed lift, drag and moment characterizations were used in NASA's Flight Optimization System ${ }^{35}$ (FLOPS) software to predict flight profiles that met takeoff, cutback, and low noise approach conditions defined in FAR 36 for noise certification. To set the model on test point during the test the measured HWB chordwise pressure distributions were matched to the measurements obtained during the aero test entry for corresponding trim conditions.

\section{Future Work Opportunities}

The results of this HWB test will provide benchmark data for propulsion airframe aeroacoustic airframe (PAA) effects including integrated twin broadband turbomachinery, dual-stream hot jets, and hybrid wing body airframe noise. However, there remains much to learn with regard to integrating aerodynamic, structural and acoustic disciplines, and specifically, their influences on free flight shielding effects. In anticipation of continuing this research past the current hybrid wing body test, the HWB model and the test apparatus are modular with versatile components to facilitate future studies.

\section{Conclusions}

A large scale, integrated model propulsion-aircraft acoustic experiment was conducted in Langley Research Center's 14 by 22 Foot Subsonic Tunnel to study basic propulsion noise, airframe noise and shielding effects relevant to a Hybrid Wing Body aircraft design and develop understanding of aircraft noise reduction approaches.

Unique testing capabilities were developed to study the interaction of engine noise and aircraft in real flow conditions. An acoustic microphone array was mounted to a traversing structure near the tunnel ceiling, in the open test cell configuration so that phased array microphone data could be used with deconvolution techniques to measure noise sources and obtain high resolution airframe noise maps. Two sideline microphone towers were built to obtain data over a larger range of directivity angles around the engine simulators and the HWB model. In addition a fuel system was added to the facility in order to provide realistic high temperature jet engine simulator flows.

This benchmark experiment should provide data for validation of new prediction methods, as well as quantification of the noise levels and source distributions of the shielded and unshielded engine configurations. This data will be used specifically to assess the HWB configuration and its potential to achieve the noise reduction goals of NASA's Environmentally Responsible Aviation Project. 


\section{Acknowledgements}

The authors would like to express their sincere gratitude to the Environmentally Responsible Aviation Project, and the COD and GFTD directorates, and to Hamilton Fernandez, Stephen Syrett, Bob Bush, Charles Niles who helped with project management and construction of facilities. We would also like to thank Stuart Pope and Jerry Plassman for their analytical support of the test, and the dedicated facility staffs at Quiet Flow Facility, Jet Noise Laboratory and the 14x22 Tunnel, especially Jaye Moen and John Swartzbaugh. Without their support this test would not have been possible.

\section{References}

${ }^{1}$ Collier, F.S., "Environmentally Responsible Aviation (ERA) Project," presentation at the NASA Fundamental Aeronautics Program, Third Annual Technical Conference, September 29-October 1, 2009, Atlanta, Georgia.

${ }^{2}$ Brooks, Thomas, "Aeroacoustic Scaling Principles and the Hybrid Wing Body Test" Tuesday Keynote Address, $17^{\text {th }}$ AIAA/CEAS Aeroacoustic Conference Portland, Oregon, USA June 6-8, 2011.

${ }^{3}$ Kawai, R.T., "Acoustic Prediction Methodology and Test Validation for an Efficient Low-Noise Hybrid Wing Body Subsonic Transport", Final Report for NASA Contract Number NNL07AA54C, February 25, 2011.

${ }^{4}$ Gatlin, Gregory M., Vicroy, Dan D., and Carter, Melissa B., Experimental Investigation of the Low-Speed Aerodynamic Characteristics of a 5.8-Percent Scale Hybrid Wing Body Configuration, 30th AIAA Applied Aerodynamics Conference, 25 - 28 June 2012, New Orleans, Louisiana, AIAA 2012-2669.

${ }^{5}$ Zorumski, W.E., "Aircraft Noise Prediction Program Theoretical Manual, Parts 1 and 2," NASA Technical Memorandum-83199-PT-1 and PT-2, National Aeronautics and Space Administration, Langley Research Center, Hampton, VA, February, 1982.

${ }^{6}$ Lopes, Leonard V. and Burley, Casey L., "Design of the Next Generation Aircraft Noise Prediction Program: ANOPP2", AIAA 2011-2854 presented at the 17th AIAA/CEAS Aeroacoustics Conference (32nd AIAA Aeroacoustics Conference) 05 - 08 June 2011, Portland, Oregon.

${ }^{7}$ National Aeronautics Research Development Plan, Biennial Update, February 2010,” The National Sciences and Technology Council, URL: http://www.whitehouse.gov/sites/default/files/microsites/ostp/aero-rdplan-2010.pdf.

${ }^{8}$ Hill, Geoffrey and Thomas, Russel H., "Challenges and Opportunities for Noise Reduction Through Advanced Aircraft Propulsion Airframe Integration and Configurations", presented at the $8^{\text {th }}$ CEAS Workshop: Aeroacoustics of New Aircraft and Engine Configurations, Budapest, Hungary, 2004.

${ }^{9}$ Huff, Dennis, "Technologies for Turbofan Noise Reduction", presented at 10th AIAA/CEAS Aeroacoustics Conference Manchester, United Kingdom, May 11, 2004.

${ }^{10}$ Envia, Edmond, "Emerging Community Noise Reduction Approaches", AIAA-2011-3532, presented at the 3rd AIAA Atmospheric and Space Environments Conference, Honolulu, Hawaii, June 27-30, 2011,

${ }^{11}$ Thomas, Russell H., Burley, Casey L., Olson, Erik D., Hybrid Wing Body Aircraft System Noise Assessment with Propulsion Airframe Aeroacoustic Experiments, International Journal of Aeroacoustics, Volume 11, number $3+4,2012$.

${ }^{12}$ Tinetti, Dunn and Pope, "Fast Scattering Code (FSC) User's Manual Version 2.0", NASA/CR-2006-214510, October 2006.

${ }^{13}$ Colas, Dorian Frederic Marie, "A diffraction integral based turbomachinery noise shielding method", Thesis, Massachusetts Institute of Technology, 2011.

${ }^{14}$ Clark, L.R. and Gerhold, C.H., "Inlet Noise Reduction By Shielding for the Blended Wing Body Airplane," AIAA Paper No. 99-1937, presented at the 5th AIAA/CEAS, Aeroacoustics Conference, Seattle, WA, 1999.

${ }^{15}$ Hill, G.A. and Thomas, R.H., "Challenges and Opportunities for Noise Reduction Through Advanced Aircraft Propulsion Airframe Integration and Configurations," presented at the $8^{\text {th }}$ CEAS Workshop on Aeroacoustics of New Aircraft and Engine Configurations, Budapest, Hungary, Nov. 11-12, 2004. 
${ }^{16}$ Hill, G.A., Brown, S.A., Geiselhart, K.A., and Burg, C.M., "Integration of Propulsion Airframe Aeroacoustic Technologies and Design Concepts for a Quiet Blended Wing Body Transport," AIAA Paper 2004-6306.

${ }^{17}$ Reimann, C. A., Tinetti, A.F., and Dunn, M.H., "Noise Scattering by the Blended Wing Body Airplane: Measurements and Prediction," AIAA Paper No. 2006-2474, presented at the $12^{\text {th }}$ AIAA/CEAS Aeroacoustics Conference, Cambridge, MA, 2006.

${ }^{18}$ Czech, Michael J., Thomas, Russell H., Elkoby, Ronen, Propulsion Airframe Aeroacoustic Integration Effects for a Hybrid Wing Body Aircraft Configuration, $16^{\text {th }}$ AIAA/CEAS Aeroacoustics Conference, 06/07/10-06/09/10, Stockholm SE, AIAA 2010-3912

${ }^{19}$ Sutliff, Daniel L., Brown, Clifford A., and Walker, Bruce E., Hybrid Wing Body Shielding Studies using an Ultrasonic Configurable Fan Artificial Noise Source Generating Simple Modes, AIAA Paper No 2012-2070, presented at the 18th AIAA/CEAS Aeroacoustics Conference, Colorado Springs, June 4-6, 2012.

${ }^{20}$ Zelina, Joseph , High Gravity (g) Combustion, AFRL-PR-WP-TR-2006-2079, Air Force Materiel Command, Air Force Research Laboratory, Wright-Patterson Air Force Base, OH 45433-7251, February 2006.

${ }^{21}$ Numerical Propulsion System Simulation $\operatorname{NPSS}^{\mathrm{TM}}$ User Guide Software Release: NPSS ${ }^{\mathrm{TM}}$ 2.2.1, Doc. \#: NPSS $^{\mathrm{TM}}$-User, Doc Revision: 1, Revision Date: 10 August 2009, NPSS ${ }^{T M}$ Software $\odot$ Copyright 2003. The United States Government, as Represented by the Administrator of the National Aeronautics and Space Administration (NASA).

${ }^{22}$ Berton, Envia and Burley, An Analytical Assessment of NASA's N+1 Subsonic Fixed $15^{\text {th }}$ AIAA/CEAS Aeroacoustics Conference (30th AIAA Aeroacoustics Conference), 05/11/09-05/13/09, Miami, FL, AIAA-20093144

${ }^{23}$ Thomas, Russell H., Czech, Michael J., and Doty, Michael J., High Bypass Ratio Jet Noise Reduction and Installation Effects Including Shielding Effectiveness, $51^{\text {st }}$ AIAA Aerospace Sciences Meeting including the New Horizon Forum and Aerospace Exposition 07-10 January 2013, Grapevine (Dallas/Ft. Worth Region), Texas, AIAA 2013-0541.

${ }^{24}$ Doty, Michael J., and Haskin, Henry H., Acoustic Characterization of Compact Jet Engine Simulator Units $19^{\text {th }}$ AIAA/CEAS Aeroacoustics Conference, June 2013, Berlin, Germany AIAA 2013-2035.

${ }^{25}$ Doty, Michael J., and Haskin, Henry H., Investigation of Flow Conditioners for Compact Jet Engine Simulator Rig Noise Reduction, 17th AIAA/CEAS Aeroacoustics Conference, 06/06/11-06/08/11, Portland, OR, AIAA 20112791.

${ }^{26}$ Doty, Michael J., Investigation of Twin Jet Aeroacoustic Properties in the Presence of a Hybrid Wing Body Shield, 18th AIAA/CEAS Aeroacoustics Conference, 06/04/12-06/06/12, Colorado Springs, CO, AIAA 2012-2157

${ }^{27}$ Brooks, Thomas F., Humphreys, William M. Jr., and Gerald E. Plassman, DAMAS Processing for a Phased Array Study in the NASA Langley Jet Noise Laboratory, AIAA 2010-3780, 16th AIAA/CEAS Aeroacoustics Conference, Stockholm, Sweden,7-9 June 2010.

${ }^{28}$ Gentry, G.L., Jr.; Quinto, P.F.; Gatlin, G. M.; and Applin, Z. T.: The Langley 14 by 22 Foot Subsonic Tunnel: Description, Flow Characteristics, and Guide for Users. NASA TP-3008, September 1990.

${ }^{29}$ Bush, Harvin, Van-Eric Parker and Reynolds, "14x22 Foot Tunnel Fuel Supply System, Bldg. 1212C, Operational Readiness Review (ORR)”, NASA Langley Research Center, Hampton Virginia, October 24, 2012.

${ }^{30}$ Humphreys, W. M., Jr., Brooks, T. F., Hunter, W. W., Jr., and Meadows, K. R., "Design and Use of Microphone Directional Arrays for Aeroacoustic Measurements", AIAA Paper 98-0471, 1998.

${ }^{31}$ Brooks, T. F., and Humphreys, W. M., Jr., "Effect of Directional Array Size on the Measurement of Airframe Noise Components", AIAA Paper 99-1958, 1999.

${ }^{32}$ Humphreys, W. M., Jr., and Brooks, T. F., "Noise Spectra and Directivity for a Scale-Model Landing Gear", International Journal of Aeroacoustics, Volume 8, Number 5, pp. 409-443, 2009.

${ }^{33}$ Brooks, T. F., and Humphreys, W. M., Jr., "A Deconvolution Approach for the Mapping of Acoustic Sources (DAMAS) Determined from Phased Microphone Arrays", Journal of Sound and Vibration, Volume 294, pp. 856879, 2006. 
${ }^{34}$ Brooks, T. F., and Humphreys, W. M., Jr., " Extension of DAMAS Phased Array Processing for Spatial Coherence Determination (DAMAS-C)", AIAA Paper 2006-2654, 2006.

${ }^{35}$ McCullers, A. Flight Optimization Systems (FLOPS) User Manual, NASA TM-206316, 1998. 